\title{
Characterization of Variable-sensitivity Compact Force Sensor using Stiffness Change of Shape- memory Polymer Based on Temperature
}

Kazuto Takashima ( $\nabla$ ktakashima@life.kyutech.ac.jp )

Kyushu Kogyo Daigaku - Wakamatsu Campus https://orcid.org/0000-0002-3304-4443

Jo Kobuchi

Kyushu Kogyo Daigaku - Wakamatsu Campus

Norihiro Kamamichi

Tokyo Denki University School of Science and Technology for Future Life: Tokyo Denki Daigaku Mirai

Kagakubu Daigakuin Mirai Kagaku Kenkyuka

\section{Kentaro Takagi}

Toyohashi University of Technology Department of Mechanical Engineering: Toyohashi Gijutsu Kagaku Daigaku Kikai Kogakukei

Toshiharu Mukai

Meijo University: Meijo Daigaku

\section{Research Article}

Keywords: Shape-memory polymer, Force sensor, Glass transition temperature, Cantilever, Strain gauge, System identification, Viscoelasticity

Posted Date: June 17th, 2021

DOl: https://doi.org/10.21203/rs.3.rs-613679/v1

License: (9) This work is licensed under a Creative Commons Attribution 4.0 International License. Read Full License

Version of Record: A version of this preprint was published at ROBOMECH Journal on November 11th, 2021. See the published version at https://doi.org/10.1186/s40648-021-00210-8. 


\section{Characterization of variable-sensitivity compact}

\section{2 force sensor using stiffness change of}

3 shape-memory polymer based on temperature

4 Kazuto Takashima ${ }^{1^{*}}$, Jo Kobuchi ${ }^{1}$, Norihiro Kamamichi ${ }^{2}$, Kentaro Takagi ${ }^{3}$ and Toshiharu

$5 \quad$ Mukai $^{4}$

6

$7 \quad{ }^{1}$ Graduate School of Life Science and Systems Engineering, Kyushu Institute of Technology,

8 2-4 Hibikino, Wakamatsu-ku, Kitakyushu 808-0196, Japan

$9 \quad{ }^{2}$ Department of Robotics and Mechatronics, School of Science and Technology for Future

10 Life, Tokyo Denki University, 5 Senju Asahi-cho, Adachi-ku, Tokyo 120-8551, Japan

3 Department of Mechanical Engineering, Toyohashi University of Technology, 1-1

Hibarigaoka, Tempaku-cho, Toyohashi 441-8580, Japan

${ }^{4}$ Department of Information Engineering, Faculty of Science and Technology, Meijo University,

1-501 Shiogamaguchi, Tenpaku-ku, Nagoya 468-8502, Japan

E-mail address of each author

K.T.: ktakashima@life.kyutech.ac.jp

J.K.: kobuchi.jo496@mail.kyutech.jp

N.K.: nkama@mail.dendai.ac.jp

K.T.: takagi@me.tut.ac.jp

T.M.: mukai@meijo-u.ac.jp

* Corresponding author. Kazuto Takashima, Graduate School of Life Science and Systems 808-0196, Japan

Tel.: +81-93-695-6030 
FAX: +81-93-695-6030

E-mail address: ktakashima@life.kyutech.ac.jp

\section{Abstract}

In the present study, we propose a variable-sensitivity force sensor using a shape-memory polymer (SMP), the stiffness of which varies according to the temperature. Since the measurement range and sensitivity can be changed, it is not necessary to replace the force sensor to match the measurement target. Shape-memory polymers are often described as two-phase structures comprising a lower-temperature "glassy" hard phase and a higher-temperature "rubbery" soft phase. The relationship between the applied force and the deformation of the SMP changes depending on the temperature. The proposed sensor consists of strain gauges bonded to an SMP bending beam and senses the applied force by measuring the strain. Therefore, the force measurement range and the sensitivity can be changed according to the temperature. In our previous study, we found that a sensor with one strain gauge and a steel plate had a small error and a large sensitivity range. Therefore, in the present study, we miniaturize this type of sensor. Moreover, in order to describe the viscoelastic behavior more accurately, we propose a transfer function using a generalized Maxwell model. We verify the proposed model experimentally and estimated the parameters by system identification. In addition, we realize miniaturization of the sensor and achieve the same performance as in our previous study. It is shown that the proposed transfer function can capture the viscoelastic behavior of the proposed SMP sensor quite well.

Keywords: Shape-memory polymer, Force sensor, Glass transition temperature, Cantilever, Strain gauge, System identification, Viscoelasticity

\section{Introduction}

Force sensors have been applied to various fields and are required to measure wider load ranges. One example in industry is a manufacturing system that has the flexibility to cope with various kinds of small-quantity production referred to as a flexible manufacturing system. Moreover, in rapidly aging societies, robotic technology has been applied to various fields, including industrial fields as well as 
nursing and welfare fields [1]. In these applications, a wide-range force sensor that can obtain load information can measure multiple biosignals, such as heart rate, respiration cycle, and weight transitions [2]. Most force sensors transform the mechanical deformation of the detection area under an applied force into a change in resistance, capacitance, or reflectance that can be measured using electric signals. For example, some force sensors consist of strain gauges bonded to a bending beam. However, with this approach, it is difficult to change the measurement range or sensitivity of a sensor, both of which depend on the material used, the type of strain gauge, and the measurement method. The deformation range depends on the sensor material, and it is difficult to change these specifications after the sensor is produced. For this reason, we previously developed a force sensor using a shape-memory polymer (SMP), the measurement range and sensitivity of which can be changed $[3,4]$.

Shape-memory polymers [3-19] are increasingly being investigated as smart materials and are used in various fields. Shape-memory polymers change their modulus around a glass transition temperature $\left(T_{\mathrm{g}}\right)$, and are often described as two-phase structures comprising a lower-temperature "glassy" hard phase and a higher-temperature "rubbery" soft phase. The hard and soft phases are characterized by two different elastic moduli: an elastic modulus for the lower-temperature, higher-stiffness glassy plateau and an elastic modulus for the higher-temperature, lower-stiffness rubbery plateau. The reversible change in the elastic modulus between the glassy and rubbery states of SMPs can be as high as several hundredfold.

Since the stiffness of the SMP can be changed according to the temperature, the measurable force range determined based on the above strain range can also be changed. Moreover, even if the strain resolution is the same, the force resolution can be changed in a similar manner. In this way, the measurement range and sensitivity of the force sensor can be changed according to the temperature. Generally, environmental stability is a very important requirement for sensors. For example, special compensating elements are often incorporated either directly into sensors or into signal conditioning circuits in order to compensate for temperature errors [20]. Note that, inverting the above idea, the proposed sensor uses the temperature-dependent changes positively.

In previous studies [3, 4], we made several prototypes of this sensor by attaching a strain gauge to an SMP sheet with an embedded electrical heating wire and evaluated their basic characteristics. Through experiments with these prototypes, which use the stiffness change of the SMP based on the temperature, we showed that the measurement range and sensitivity can be changed without replacing the actual sensor [3]. On the other hand, the changes in measurement range and sensitivity (ranging 
1 from a hundredfold to a thousandfold) depend on the Young's modulus of the SMP and are not adjustable. However, the change may be too large for some applications. We also affixed a thin steel plate to reduce the influence of the difference in elastic modulus between the strain gauges and the SMP sheet. This made it possible to reduce the discrepancy between the theoretical values and the measured values. Moreover, SMP force sensors with either one or two strain gauges and steel plates were fabricated, and their accuracy and sensitivity were investigated under the same conditions [4]. Experiments using the prototypes demonstrated that a sensor with one steel plate had a small error and a large sensitivity range although the dimensions of the sensors were not optimized.

Therefore, in the present study, we miniaturized this type of sensor for practical use. A prototype of this sensor was made by attaching a strain gauge to an SMP sheet with an embedded electrical heating wire, and we evaluated the basic characteristics of the prototype sensor.

In a previous study, we proposed a theoretical formula that took the viscosity of the SMP into consideration, which made it possible to reduce the effect of stress relaxation [4]. However, since the first derivative of the measurement values was used to estimate the force (see "Basic concept of the force sensor" and "Generalized Maxwell model" sections for additional details), the measurement errors could be large. Therefore, in the present study, we propose a transfer function method using a generalized Maxwell model. We verified the proposed model experimentally and estimated the parameters by system identification.

\section{Basic concept of the force sensor}

As shown in Fig. 1, the force sensor was fabricated by bonding an SMP sheet and a steel plate and attaching a strain gauge to the steel. If the viscosity of the SMP and the embedded wire are negligible, by assuming a composite beam consisting of SMP and steel sheets, then the strain on the strain gauge ( $\varepsilon$ ) can be expressed as follows $[3,4,21]$ :

$$
W=\frac{\left(E_{\mathrm{p}} I_{\mathrm{p}}^{\prime}+E_{\mathrm{s}} I_{\mathrm{s}}^{\prime}\right) \varepsilon}{\left(h_{\mathrm{p}}+h_{\mathrm{s}}-h_{\mathrm{l}}\right) x}
$$

where $x$ is the distance between the strain gauge and the position at which the force is applied, $E_{\mathrm{p}}$ and $E_{\mathrm{s}}$ are the elastic moduli of the SMP and steel, respectively, and $I_{\mathrm{p}}{ }^{\prime}$ and $I_{\mathrm{s}}{ }^{\prime}$ are the area moments of inertia for the SMP and steel, respectively, about the neutral axis of the composite beam. Here, $I_{\mathrm{p}}$ ' and $I_{\mathrm{s}}$ are expressed as follows: 


$$
I_{\mathrm{p}}^{\prime}=\frac{b h_{\mathrm{p}}^{3}}{12}+\left(h_{1}-\frac{h_{\mathrm{p}}}{2}\right)^{2} b h_{\mathrm{p}}
$$

$$
I_{\mathrm{s}}^{\prime}=\frac{b h_{\mathrm{s}}^{3}}{12}+\left(h_{\mathrm{p}}-h_{1}+\frac{h_{\mathrm{s}}}{2}\right)^{2} b h_{\mathrm{s}}
$$

where $b$ is the width of the beam, $h_{\mathrm{p}}$ and $h_{\mathrm{s}}$ are the thicknesses of the SMP and steel plates, respectively, and $h_{1}$ is the distance between the neutral axis and the SMP surface and is expressed as follows:

$$
h_{1}=\frac{E_{\mathrm{p}} h_{\mathrm{p}}^{2}+E_{\mathrm{s}}\left(2 h_{\mathrm{p}} h_{\mathrm{s}}+h_{\mathrm{s}}^{2}\right)}{2\left(E_{\mathrm{p}} h_{\mathrm{p}}+E_{\mathrm{s}} h_{\mathrm{s}}\right)}
$$

As described "Introduction" section, $E_{\mathrm{p}}$ can be changed according to the temperature. Therefore, the relationship between $\varepsilon$ and $W$ given in Eq. (1) can also be changed. Therefore, the change in the measurement range based on temperature can be modified. Moreover, as shown in Eq. (1), by changing the thickness of the steel plate, the measurement range and the sensitivity of the sensor can be modified.

\section{[Insert Fig. 1 here]}

In order to understand the mechanisms producing such unique properties and to design products including SMPs, various mathematical models have been proposed [5, 6, 12-19, 22]. To investigate relaxation processes in polymers, combinations of elements, including springs and dashpots, are widely used for modeling under isothermal conditions [12-18, 22]. For example, Tobushi et al. proposed a linear constitutive model by modifying a three-element viscoelastic model combining two springs and a dashpot to represent the deformation characteristics of the SMP [12]. Similarly, in our previous study [4], considering the viscosity of the SMP, we assumed that the relationship between $W$ and $\varepsilon$ is given by

$$
\dot{W}=L\left(\dot{\varepsilon}-\frac{W}{M}+\frac{\varepsilon}{N}\right)
$$

where $L, M$, and $N$ are constants. 
2 Compact sensor

3 Design of compact sensor

4 The dimensions of the prototype SMP sensors used in our previous study [4] and the present study are shown in Table 1. Here, $l$ is the length of the sensor. The dimensions of the prototype sensor constructed in the present study are similar to those of the commercial force sensor (LVS-2KA $\left(T<T_{\mathrm{g}}\right.$ ), LVS-200GA $\left(T>T_{\mathrm{g}}\right)$, Kyowa Electronic Instruments Co., Ltd.) used in the experiment. The volume of the proposed sensor was reduced by $87 \%$ compared with that in our previous study. In our previous study, we applied a deformation of $5 \mathrm{~mm}$ to the tip of the sensor. In the present study, we determined $b$ and $h_{\mathrm{p}}$ so that the reaction force $W$ is the rated capacity of a commercial load cell $(20 \mathrm{~N})$ when the deformation is $1 \mathrm{~mm}$ below $T_{\mathrm{g}}$. The ratio of the sensor length $(14 \mathrm{~mm})$ to the deformation $(1 \mathrm{~mm})$ is approximately the same as that in the previous study, because the large creep strain of the SMP below $T_{\mathrm{g}}$ is not recovered [7]. The thickness of the steel plate $\left(h_{\mathrm{s}}=0.07 \mathrm{~mm}\right)$ is similar to that in our previous study [4]. The relationship between the applied force $W$ and the deflection $y$ is expressed as follows:

$$
y=\frac{W l^{3}}{3\left(E_{\mathrm{p}} I_{\mathrm{p}}^{\prime}+E_{\mathrm{s}} I_{\mathrm{s}}^{\prime}\right)}
$$

where $l(=11 \mathrm{~mm})$ is the distance between the fixed end and the position at which the force is applied. In the present study, we chose a polyurethane SMP (SMP Technologies Inc., MP4510, $T_{\mathrm{g}}=45^{\circ} \mathrm{C}$ ). The fundamental characteristics of this material taken from the product catalogue are listed in Table 2. Substituting $E_{\mathrm{p}}=1,350 \mathrm{MPa}\left(T<T_{\mathrm{g}}\right)$ and $E_{\mathrm{s}}=193 \mathrm{GPa}$ into this equation, we obtain $W=27 \mathrm{~N}$.

[Insert Table 1 here]

[Insert Table 2 here]

\section{Prototype}

The prototype SMP force sensor is shown in Fig. 2. In the present study, we prepared an SMP sheet with an embedded electrical heating wire in a manner similar to that described in our previous studies $[4,8]$. The shape and dimensions of the heating wire (outer diameter: $0.26 \mathrm{~mm}$, electrical resistivity: $\left.108 \times 10^{6} \Omega \cdot \mathrm{cm}\right)$ are shown in Fig. 3. The underlined lengths in the figure were smaller than those in our previous study. The total electrical resistivity was $1.8 \Omega$. 
We bonded the SMP sheet and steel plate (SUS304H, thickness: $0.07 \mathrm{~mm}$ ) using an adhesive (PPX, Cemedine Co., Ltd.). We attached one strain gauge (KFGS-2-120-C1-16 L1M2R, Kyowa Electronic Instruments Co., Ltd.) to the steel plate and measured the strain on the surface of the steel plate. The distance between the strain gauge position and the position at which the force was applied $(x)$ was 7 mm. We used a cyanoacrylate adhesive (CC-36, Kyowa Electronic Instruments Co. Ltd., operating temperature range: -30 to $\left.100^{\circ} \mathrm{C}\right)$.

The heating wire was connected to a power supply (PE18-1.3AT, KENWOOD) with a stable direct current, and voltages of $5 \mathrm{~V}$ were supplied to the prototype sensor. With a thermocouple attached to the surface of the SMP sheet (red circle in Fig. 2), we heated the sheet and maintained a temperature of $70^{\circ} \mathrm{C}$, as in our previous study [4]. When the SMP was heated from room temperature to $70^{\circ} \mathrm{C}$, we set the duty ratio to $100 \%$ and then modified it to compensate for the heat loss and maintain the SMP temperature at $70^{\circ} \mathrm{C}$ A thermogram of the heated SMP sheet captured by an infrared thermal camera (NEC Avio Infrared Technologies Co., Ltd., F30W) is shown in Fig. 4. The entire sheet was heated uniformly to approximately $70^{\circ} \mathrm{C}$. One reason for the temperature uniformity is the reduced distance between the heating wire segments. Since the tape covered the surface to attach the thermocouple, the center of the SMP sheet is shown in blue.

\section{[Insert Fig. 4 here]}

We created a base, a presser plate, and a cover using a 3D printer (Fig. 5). The prototype force sensor in Fig. 2 was fixed between the presser plate and the base. As shown in Fig. 5(b), the total sensor dimensions including these parts are almost same as those of a commercial load cell (LVS-A,

\section{Experiments}


1 The experimental apparatus is shown in Fig. 6. The applied force was measured at temperatures above and below $T_{\mathrm{g}}$. The experiments below $T_{\mathrm{g}}$ were performed at room temperature. The relationship between the strain and the force applied using an indenter connected to the load cell was then evaluated. The indenter was placed in contact with the steel plate of the prototype sensor in order to prevent SMP surface deformation. The load cell and the sensor were attached to a manual stage and an automatic stage (OSMS20-85, Sigma Koki Co., Ltd.), respectively. The prototype sensor was automatically displaced using the automatic stage. The strain gauge was connected to a PC through a bridge box (DB-120A, Kyowa Electronic Instruments Co., Ltd.) and a strain amplifier (DPM-711B, Kyowa Electronic Instruments Co., Ltd.). The load cell was also connected to the PC through a strain amplifier. The sampling frequency was $1 \mathrm{kHz}$. We resampled the obtained $1-\mathrm{kHz}$ signal at $100 \mathrm{~Hz}$ using the resample() function in MATLAB.

[Insert Fig. 6 here]

\section{Experiment 1}

We performed two types of experiments in order to characterize the proposed sensor. We first applied a random force to the prototype sensor in order to estimate the optimum transfer function and compare the proposed sensor with that used in our previous study [4]. The sensor was deformed as follows:

Step 1: The sensor was held motionless in the unloaded state (just before touching).

Step 2: After the unloaded state, the sensor was moved in the direction of the blue arrow in Fig. 6 and was brought into contact with the load cell to apply a deformation of $1 \mathrm{~mm}$ to the tip of the sensor.

Step 3: Leaving the tip deformed, the sensor was held motionless.

Step 4: The sensor was returned to the initial position.

Steps 1 through 4 were repeated. The number of repetitions was 5, 10, and 20, which were larger than in our previous study [4]. For system identification, the input should be persistently exciting, i.e., it should contain many distinct frequencies [23]. Therefore, in the present study, considering the potential applications of our sensor (i.e., a wide range of inputs), we randomly set the velocity in Steps 2 and 4 from 0 to $5 \mathrm{~mm} / \mathrm{s}$, and the rest time in Steps 1 and 3 from 0 to $10 \mathrm{~s}$. For each condition, the measurements were conducted six times. We evaluated two prototype sensors (samples 1 and 2). 


\section{Experiment 2}

We then evaluated the dynamic response of the proposed sensor to a step deformation. Similarly to experiment 1 , the sensor was deformed as follows:

Step 1: The sensor was held motionless in the unloaded state (just before touching) for $10 \mathrm{~s}$.

Step 2: After the unloaded state, the sensor was moved in the direction of the blue arrow in Fig. 6 and was brought into contact with the load cell in order to apply a deformation to the tip of the sensor.

Step 3: Leaving the tip deformed, the sensor was held motionless for $300 \mathrm{~s}$.

We set the deformation in Step 2 to $0.25,0.5,0.75$, or $1 \mathrm{~mm}$ in order to check whether the force increases with increasing deformation. For each condition, the measurements were conducted three times. We evaluated two prototype sensors (samples 1' and 2').

\section{Transfer function}

\section{Generalized Maxwell model}

Here, $\dot{\varepsilon}$ and $\varepsilon$ are measured by the strain gauges, so $\dot{W}$ is determined using Eq. (5) and the value of $W$ at each time step. If $W=0$ at $t=0$, the value of $\dot{W}$ determined from Eq. (5) can be substituted into Eq. (7) in order to sequentially calculate $W$ :

$$
W(t+\mathrm{d} t)=W(t)+\dot{W}(\mathrm{t}) \mathrm{d} t
$$

In our previous study [4], after performing this procedure multiple times, the force measured using the load cell was compared with $W$ obtained based on the strain measured using the strain gauge, and the error was calculated. Then, $W$ was determined by combining the theoretical equations in "Basic concept of the force sensor" section. In MATLAB, the least-squares method was then used to determine the optimum values of $L, M$, and $N$ in Eq. (5).

In the present study, in order to describe the viscoelastic behavior more accurately, we derived a transfer function using the generalized Maxwell model, as shown in Fig. 7 [13]. Westbrook developed a generalized Maxwell model to capture the shape-memory effect using two sets of nonequilibrium branches for two fundamentally different modes of relaxation: the glassy mode and the Rouse modes 
1 [13]. Since the temperature of our sensor is fixed above and below $T_{\mathrm{g}}$, we neglected the thermal 2 expansion of the SMP. Then, using the transfer function, we calculated the force from the strain. 3

\section{[Insert Fig. 7 here]}

The derivation process is shown below. As shown in Fig. 7, the forces applied to each element $f_{0}$, $f_{i}(i=1 \cdots n)$ are expressed as follows:

$$
\begin{gathered}
f_{i}=\frac{A E_{i}}{L_{2}} u_{i s}=\frac{A \eta_{i}}{L_{1}} \dot{u}_{i d} \\
f_{0}=\frac{A E_{0}}{L} u
\end{gathered}
$$

where $A$ is the cross-sectional area, $u_{i d}$ and $u_{i s}$ are the displacements of the dashpot and the spring, respectively, $\eta_{i}$ is the viscosity, $E_{0}$ and $E_{i}$ are elastic moduli, $L$ is the total length of the proposed model, and $L_{1}$ and $L_{2}$ are the length of the dashpot and the spring, respectively. The total applied force $(f)$ and the displacement $(u)$ of the model are expressed as follows:

$$
f=f_{0}+\sum_{i=1}^{n} f_{i}
$$

$$
u=u_{i s}+u_{i d}
$$

Using Eqs. (8) and (11), we have

$$
\dot{u}=\dot{u}_{i s}+\dot{u}_{i d}=\frac{L_{2}}{A E_{i}} \dot{f}_{l}+\frac{L_{1}}{A \eta_{i}} f_{i}
$$

By Laplace transformation of Eqs. (9) and (12), we obtain

$$
F_{0}(s)=\frac{A E_{0}}{L} U(s)
$$

where 


$$
B_{i}=\frac{L_{2}}{A E_{i}}
$$

$$
C_{i}=\frac{L_{1}}{A \eta_{i}}
$$

3

4

After Laplace transformation of Eq. (10), by substituting Eqs. (13) and (14), we have

$$
\begin{aligned}
F(s) & =F_{0}(s)+\sum_{i=1}^{n} F_{i}(s) \\
& =U(s)\left(\frac{A E_{0}}{L}+\sum_{i=1}^{n} \frac{s}{B_{i} s+C_{i}}\right)
\end{aligned}
$$

Using Eq. (17), the transfer function $G_{1}(s)$ for the generalized Maxwell model, shown in Fig. 7, with an input $U(s)$ and an output $F(s)$, is expressed as follows:

$$
G_{1}(s)=\frac{A E_{0}\left(B_{1} s+C_{1}\right)\left(B_{2} s+C_{2}\right) \cdots\left(B_{n} s+C_{n}\right)}{+s L\left\{\begin{array}{c}
\left(B_{2} s+C_{2}\right)\left(B_{3} s+C_{3}\right) \cdots\left(B_{n} s+C_{n}\right)+\cdots \\
+\left(B_{1} s+C_{1}\right)\left(B_{2} s+C_{2}\right) \cdots\left(B_{n-1} s+C_{n-1}\right)
\end{array}\right\}}
$$

As shown in Eq. (18), the numbers of poles and zeros are $n$. In the present study, we assumed that the transfer function $G(s)$ with an input $\varepsilon(s)$ and an output $W(s)$ had a structure similar to $G_{1}(s)$ and $n$ poles and $n$ zeros. Namely, $G(s)$ is expressed as follows:

$$
G(s)=\frac{\alpha_{n} s^{n}+\cdots+\alpha_{1} s+\alpha_{0}}{\beta_{n} s^{n}+\cdots+\beta_{1} s+\beta_{0}}
$$

Since the temperature of the proposed sensor is fixed above or below $T_{\mathrm{g}}$, we assumed that $\alpha_{i}(i=$ $0 \cdots n)$ and $\beta_{i}(i=0 \cdots n)$ are constants in the rubbery and glassy states. Note that by Laplace transformation of Eq. (5), $G(s)$ with $n=1$ can be obtained. We determined $n$ using the experimental results.

\section{Calculation of force}

Using the results of experiments 1 and 2 shown in "Experiments" section, we first estimated the transfer function shown in Eq. (19) and calculated the fit ratio [24]. The fit ratio (hereinafter denoted as FIT) is defined as 


$$
\mathrm{FIT}=\left\{1-\frac{\sqrt{\sum_{k=1}^{m}\{\hat{y}(k)-y(k)\}^{2}}}{\sqrt{\sum_{k=1}^{m}\{y(k)-\bar{y}\}^{2}}}\right\} \times 100 \%
$$

2

where $y(k)$ and $\hat{y}(k)$ are the measured output and the simulated output, respectively, at time $k, \bar{y}$ is the average value of $y$, and $m$ is the number of samples. When $y(k)$ is identical to $\hat{y}(k)$ for all $k=1, \ldots$, $m$, FIT becomes 100 . The procedure is as follows:

- Method 1 (proposed in the present study): We estimated $G(s)(n=1-5)$ using the tfest () function in MATLAB. For the estimation, we imposed the condition that $\alpha_{i}$ and $\beta_{i}$ are positive because the values of $L, A, E_{0}, B_{i}$, and $C_{i}$ in Eq. (18) are positive. We then calculated FIT using the compare() function. Comparing FIT for each condition, we determined the optimal value of $n$.

Furthermore, using the method in our previous study [4] (namely Eqs. (5) and (7), method 2) and the results of experiment 1 , we estimated $W$, calculated FIT, and compared the obtained results with those measured by Method 1. The procedure is as follows.

- Method 2 (used in our previous study): Using Eqs. (5) and (7), we calculated $L, M$, and $N$. In MATLAB, the least-squares method was used to determine the optimum values of $L, M$, and $N$ in Eq. (5). Here, $L, M$, and $N$ were changed at intervals of $10 \mathrm{~N} \cdot \mathrm{s}^{-1}, 10 \mathrm{Ns}$, and $0.1 \mathrm{~s}$, respectively. Based on these values, we also calculated FIT.

\section{Results and discussion}

\section{Identification of transfer function (experiment 1, method 1)}

Typical transitions of the force below and above $T_{\mathrm{g}}$ are shown in Fig. 8. As shown in Fig. 8, the two measured forces are almost identical. Moreover, by considering the viscosity of the SMP, the estimated force can reproduce the stress relaxation phenomenon. The maximum force and strain for different conditions are shown in Fig. 9. Although we applied a similar displacement below and above $T_{\mathrm{g}}$, the measured force range is significantly different. Based on the above results, it was shown that the miniaturized sensor achieved the same performance as in our previous study. On the other hand, the maximum strain below and above $T_{\mathrm{g}}$ are similar. The measured force below $T_{\mathrm{g}}$ is smaller than expected (27 N, see "Design of compact sensor" section for additional details) and both the maximum force and strain are different for the two prototype sensors. These differences may be attributed to errors during sensor manufacture.

[Insert Fig. 8 here] 
[Insert Fig. 9 here]

On the other hand, when the sensor was returned to the initial position, the force measured by the load cell became zero although the estimated values were not zero. One reason is that the SMP sheet could not recover to the initial shape quickly because of its viscosity, and the indenter of the load cell could not contact the prototype sensor. Above $T_{\mathrm{g}}$, a fluctuation of the estimated force can be seen. The transitions of the measured strain are shown in Fig. 10. Similarly to Fig. 8, fluctuations can also be seen, and are attributed to electrical noise in the heating wire.

\section{[Insert Fig. 10 here]}

Using Method $1(n=1-5)$, we calculated FIT. The mean \pm the standard deviation below and above $T_{\mathrm{g}}$ are shown in Figs. 11(a) and 11(b), respectively. When $n=4$ and 5, by imposing the condition that $\alpha_{i}$ and $\beta_{i}$ are positive, an error occurred during the calculation in MATLAB. Therefore, the results are not shown in Fig. 11. The values of FIT below $T_{\mathrm{g}}$ are larger than those above $T_{\mathrm{g}}$. One reason would be the electrical noise shown in Figs. 8 and 10.

\section{[Insert Fig. 11 here]}

We then calculated the average values of the coefficients in Eq. (19) below and above $T_{\mathrm{g}}$, and determined $G(s)$ with $n=1,2$, and 3. Using the same experimental results, we calculated the mean and the standard deviation of FIT below and above $T_{\mathrm{g}}$ for each $n$. The calculated FIT values are shown in Fig. 12; the largest value was obtained for $n=3$. As shown in Fig. 12(a), when $n=2$ below $T_{\mathrm{g}}$, FIT was the smallest. This could be attributed to factors such as the mass and shape of the sensor, which were not considered in the proposed model.

\section{[Insert Fig. 12 here]}

Bode diagrams of the transfer function $(n=3)$ obtained using Method 1 below and above $T_{\mathrm{g}}$ are shown in Fig. 13. It can be seen that the gain has a significant temperature dependence. The phases above $T_{\mathrm{g}}$ were larger than those below $T_{\mathrm{g}}$, which can be attributed to the viscosity of the SMP. 
Comparison with our previous studies (experiment 1, comparison between Methods 1 and 2)

The FIT values determined using Method 2 are shown in Fig. 14. As shown in Figs. 11 and 14, the largest values of FIT determined using Method 1 were larger than those determined using Method 2. Using the proposed transfer function model, the FIT values became larger than those in our previous studies.

Bode diagrams of the transfer function obtained using Method 2 below and above $T_{\mathrm{g}}$ are shown in

Fig. 15. The gains in Fig. 15 are similar to those in Fig. 13. However, above $T_{\mathrm{g}}$, the phases in Fig. 15 are smaller than those in Fig. 13. This difference would cause a decrease in FIT.

[Insert Fig. 15 here]

\section{Step deformation response (Experiment 2)}

Using Method $1(n=1-3)$ and the results of experiment 2, we calculated FIT for different conditions. The mean \pm the standard deviation below and above $T_{\mathrm{g}}$ are shown in Figs. 16(a) and 16(b), respectively. When $n=4$ and 5, an error occurred during the calculation in MATLAB. Similarly to experiment 1, Figure 16 shows excellent agreement between the model estimations and the experimental data, although the deformations of the SMP sensors were not the same. As shown in Figs. 11(b) and 16(b), above $T_{\mathrm{g}}$, the values of FIT in experiment 2 were smaller than those in experiment 1 . One reason would be the changes in the temperature and the sensor characteristics over time because experiment 2 (more than $310 \mathrm{~s}$ ) was longer than experiment 1 (about $130 \mathrm{~s}$ ).

We then calculated the average values of the coefficients in Eq. (19) below and above $T_{\mathrm{g}}$, and 
1 determined $G(s)$ for $n=1,2$, and 3. Using the same experimental results, we calculated the mean and

2 the standard deviation of FIT below and above $T_{\mathrm{g}}$ for each $n$. The calculated values of FIT are shown

3 in Fig. 17, and are seen to be much lower than those in Fig. 16. The main reason is that the coefficients

4 in Eq. (19) are different for each deformation. Therefore, for practical applications of the proposed

5 sensor, it would be necessary to set the optimum coefficients according to the operating conditions.

6

$7 \quad$ [Insert Fig. 17 here]

8

\section{Conclusion}

10 We have developed a variable-sensitivity force sensor using an SMP sheet with an embedded electrical heating wire. In the present study, we miniaturized this type of sensor while referencing the dimensions and rated capacity of a commercial load cell. The volume was decreased by $87 \%$ compared with that in our previous study. The entire sheet of the prototype sensor was heated uniformly to approximately $70^{\circ} \mathrm{C}$.

Moreover, we proposed a transfer function using a generalized Maxwell model. Using identification experimental results, we determined the numbers of poles and zeros and compared the FIT value between our previous and present studies. Models were introduced and were validated experimentally, and there was excellent agreement between the model estimations and the experimental data. A transfer function with $n=3$ was found to be optimal. Using the proposed model, the FIT value became larger than in our previous studies.

\section{Declarations}

\section{Availability of data and material}

Not applicable.

\section{Competing interests}

27 The authors declare that they have no competing interests.

\section{Funding}

The present study was supported by JSPS KAKENHI Grant Numbers JP17K06265 and JP20K04401. 


\section{Authors' contributions}

KT conceived and led the study, and wrote this paper as corresponding author. JK developed the sensor, carried out all experiments, and analyzed data. NK, KT and TM participated in the research design. All authors read and approved the final manuscript.

\section{Acknowledgements}

Not applicable.

\section{References}

1. Mukai T, Hirano S, Nakashima H, et al (2011) Manipulation Using Tactile Information for a Nursing-Care Assistant Robot in Whole-Body Contact with the Object. Trans JAPAN Soc Mech Eng Ser C 77:3794-3807 . doi: 10.1299/kikaic.77.3794

2. Murozaki Y, Sakuma S, Arai F (2017) Improvement of the Measurement Range and Temperature Characteristics of a Load Sensor Using a Quartz Crystal Resonator with All Crystal Layer Components. Sensors 17:1067 . doi: 10.3390/s17051067

3. Takashima K, Kamizono H, Takenaka M, Mukai T (2017) Force sensor utilizing stiffness change of shape-memory polymer based on temperature. ROBOMECH J 4:17 . doi: 10.1186/s40648-017-0086-2

4. Takashima K, Onoda R, Mukai T (2018) Evaluation of Error and Sensitivity for Force Sensor Using Shape-Memory Polymer. In: 2018 57th Annual Conference of the Society of Instrument and Control Engineers of Japan, SICE 2018. Institute of Electrical and Electronics Engineers Inc., pp 1433-1438

5. Barot G, Rao IJ (2006) Constitutive modeling of the mechanics associated with crystallizable shape memory polymers. Zeitschrift fur Angew Math und Phys 57:652-681 . doi: 10.1007/s00033-005-0009-6

6. Wang ZD, Li DF, Xiong ZY, Chang RN (2009) Modeling thermomechanical behaviors of shape memory polymer. J Appl Polym Sci 113:651-656 . doi: 10.1002/app.29656

7. Tobushi H, Hara H, Yamada E, Hayashi S (1996) Thermomechanical properties in a thin film of shape memory polymer of polyurethane series. Smart Mater Struct 5:483-491 . doi: $10.1088 / 0964-1726 / 5 / 4 / 012$

8. Takashima K, Sugitani K, Morimoto N, et al (2014) Pneumatic artificial rubber muscle using 
shape-memory polymer sheet with embedded electrical heating wire. Smart Mater Struct 23:125005 . doi: 10.1088/0964-1726/23/12/125005

9. Takashima K, Noritsugu T, Rossiter J, et al (2012) Curved type pneumatic artificial rubber muscle using Shape-Memory Polymer. J Robot Mechatronics 24:472-479

10. Abavisani I, Rezaifar O, Kheyroddin A (2021) Multifunctional Properties of Shape Memory Materials in Civil Engineering Applications: a State-of-the-Art Review. J Build Eng 102657 . doi: $10.1016 /$ j.jobe.2021.102657

11. An Y, Okuzaki H (2020) Novel electro-Active shape memory polymers for soft actuators. Jpn J Appl Phys 59:061002 . doi: 10.35848/1347-4065/ab8e08

12. Tobushi H, Hashimoto T, Hayashi S, Yamada E (1997) Thermomechanical Constitutive Modeling in Shape Memory Polymer of Polyurethane Series. J Intell Mater Syst Struct 8:711718 . doi: $10.1177 / 1045389 X 9700800808$

13. Westbrook KK, Kao PH, Castro F, et al (2011) A 3D finite deformation constitutive model for amorphous shape memory polymers: A multi-branch modeling approach for nonequilibrium relaxation processes. Mech Mater 43:853-869 . doi: 10.1016/j.mechmat.2011.09.004

14. Niwa Y, Ikeda T, Senba A (2014) Micromechanical model of shape memory polymer including temperature-strain history dependence. Trans JSME (in Japanese) 80:SMM0310SMM0310 . doi: 10.1299/transjsme.2014smm0310

15. Leng J, Lan X, Liu Y, Du S (2011) Shape-memory polymers and their composites: Stimulus methods and applications. Prog. Mater. Sci. 56:1077-1135

16. Kim JH, Kang TJ, Yu WR (2010) Thermo-mechanical constitutive modeling of shape memory polyurethanes using a phenomenological approach. Int J Plast 26:204-218 . doi: 10.1016/j.ijplas.2009.06.006

17. Diani J, Liu Y, Gall K (2006) Finite strain 3D thermoviscoelastic constitutive model for shape memory polymers. Polym Eng Sci 46:486-492 . doi: 10.1002/pen.20497

18. Wang Y, Wang J, Peng X (2021) Refinement of a 3D finite strain viscoelastic constitutive model for thermally induced shape memory polymers. Polym Test 96:107139 . doi: 10.1016/j.polymertesting.2021.107139

19. Liu Y, Gall K, Dunn ML, et al (2006) Thermomechanics of shape memory polymers: Uniaxial experiments and constitutive modeling. Int $\mathbf{J}$ Plast 22:279-313 . doi: 10.1016/j.ijplas.2005.03.004 
1 20. Fraden J (2003) Handbook of modern sensors: Physics, designs, and applications. Third Edition. Springer-Verlag

21. Shibata T, Otani R, Komai K, Inoue T (1991) Zairyo Rikigaku No Kiso. Baifukan, Tokyo

22. Kawahara T, Tokuda K, Tanaka N, Kaneko M (2006) Noncontact impedance sensing. Artif Life Robot 10:35-40 . doi: 10.1007/s10015-005-0363-7

23. Ljung L (1999) System Identification: Theory for the User, 2nd Edition | Pearson. Prentice Hall

24. Muroi H, Adachi S (2015) Model Validation Criteria for System Identification in Time Domain. IFAC-PapersOnLine 48:86-91 . doi: 10.1016/j.ifacol.2015.12.105

\section{Figure Captions}

Fig. 1 Bending state of beam

Fig. 2 Prototype force sensor using an SMP sheet with an embedded electrical heating wire. We attached a thermocouple to the surface of the SMP sheet at the position indicated by the red circle

Fig. 3 Heating wire. The underlined lengths are smaller than those in our previous study

Fig. 4 Thermogram of SMP force sensor when heated and maintained at $70^{\circ} \mathrm{C}$

Fig. 5 Prototype force sensor using SMP. (a) External appearance. (b) Internal components

Fig. 6 Experimental apparatus for evaluating force sensor. The prototype sensor was automatically displaced using an automatic stage

Fig. 7 Generalized Maxwell model used in present study

Fig. 8 Forces measured using prototype sensor and load cell when random force was applied. FIT values are shown in each figure. (a) $T<T_{\mathrm{g}}(n=1)$. (b) $T>T_{\mathrm{g}}(n=1)$. (c) $T<T_{\mathrm{g}}(n=2)$. (d) $T>T_{\mathrm{g}}(n=2)$. (e) $T<T_{\mathrm{g}}(n=3)$. (f) $T>T_{\mathrm{g}}(n=3)$ 
2 Fig. 9 Maximum force (a) and strain (b) for different conditions

3

4 Fig. 10 Transition of measured strain. (a) $T<T_{\text {g. }}$ (b) $T>T_{\text {g. }}$. We resampled the obtained $1-\mathrm{kHz}$ signal at $100 \mathrm{~Hz}$ using the resample() function of MATLAB

6

Fig. 11 FIT values for different conditions. (a) $T<T_{\mathrm{g}}$. (b) $T>T_{\mathrm{g}}$

8

Fig. 12 Average FIT values for different conditions. (a) $T<T_{\mathrm{g}}$. (b) $T>T_{\mathrm{g}}$

Fig. 13 Frequency responses of transfer function obtained using Method 1. (a) \#1. (b) \#2

Fig. 14 FIT value obtained using Method 2

Fig. 15 Frequency responses of transfer function obtained using Method 2. (a)\#1. (b) \#2 16

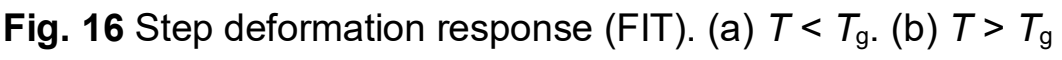

Fig. 17 Average step deformation response (FIT). (a) $T<T_{\mathrm{g}}$ (b) $T>T_{\mathrm{g}}$ 
Figures

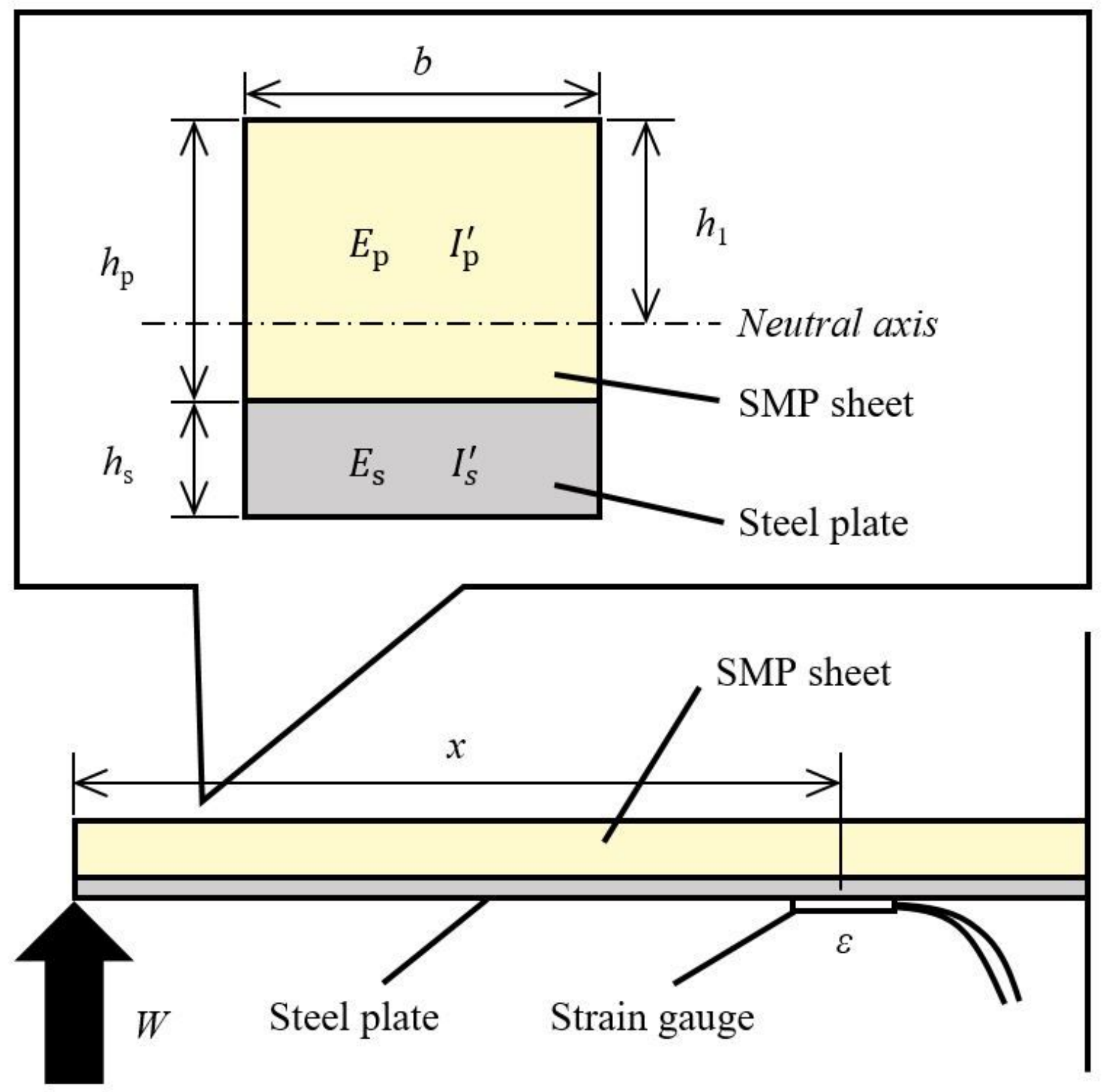

Figure 1

Bending state of beam 


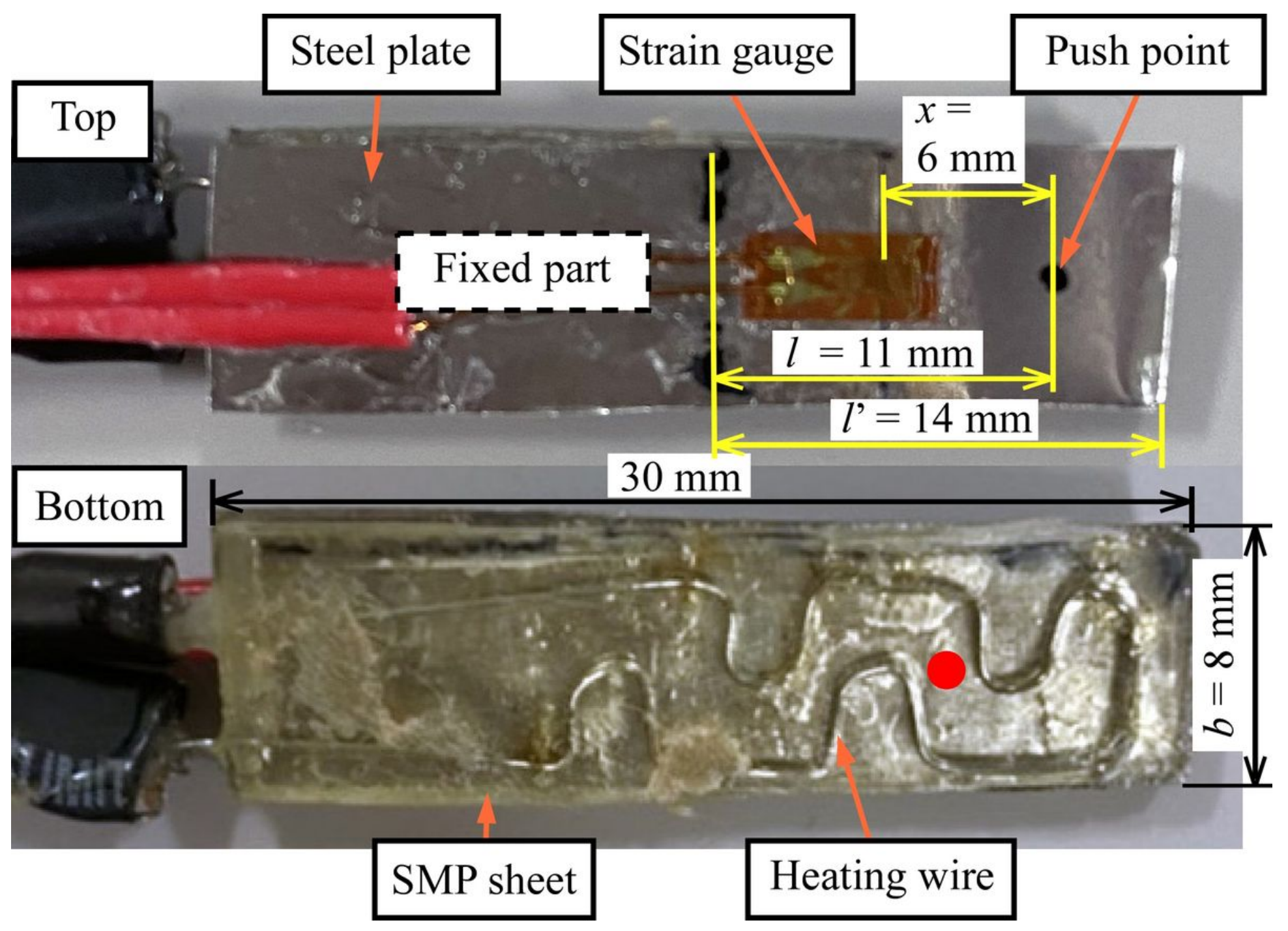

Figure 2

Prototype force sensor using an SMP sheet with an embedded electrical heating wire. We attached a thermocouple to the surface of the SMP sheet at the position indicated by the red circle

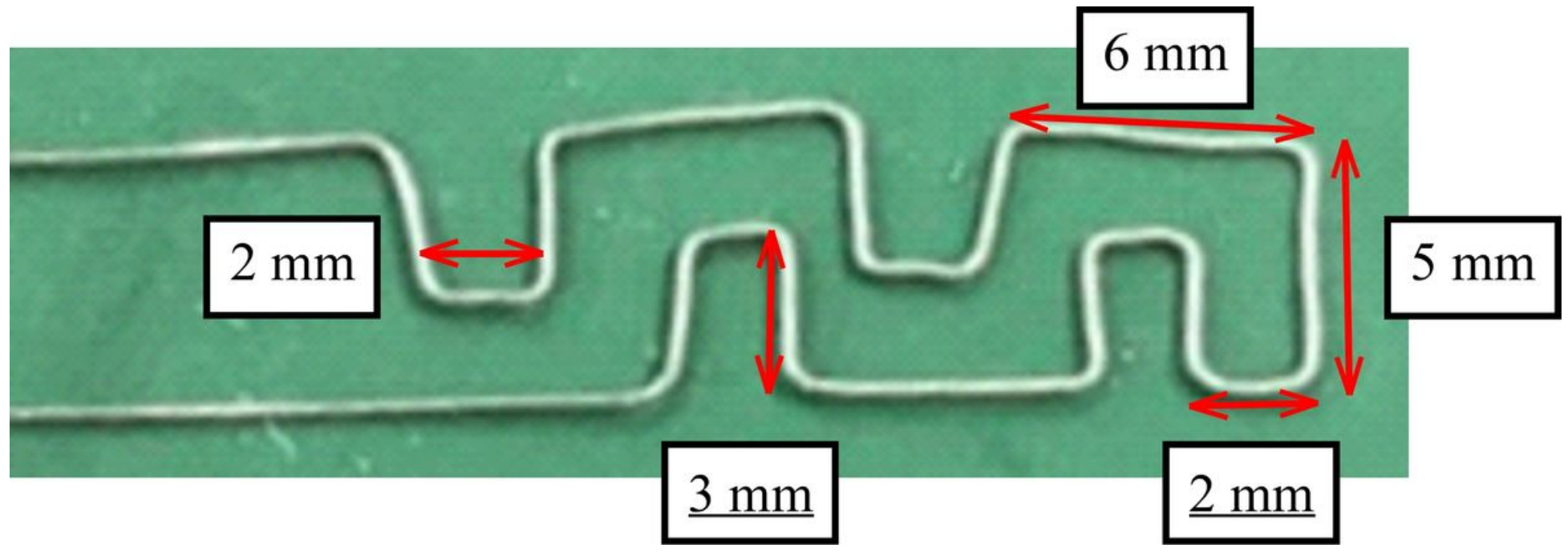

Figure 3 
Heating wire. The underlined lengths are smaller than those in our previous study

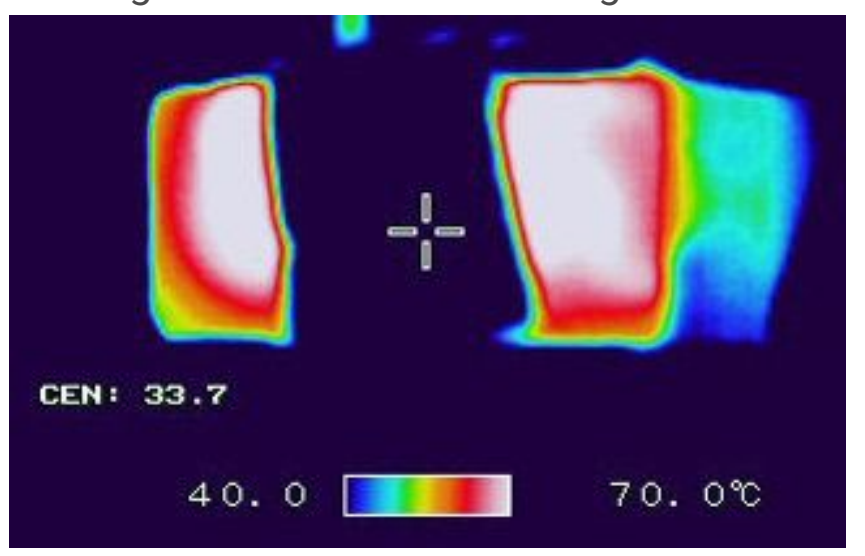

Figure 4

Thermogram of SMP force sensor when heated and maintained at $70^{\circ} \mathrm{C}$
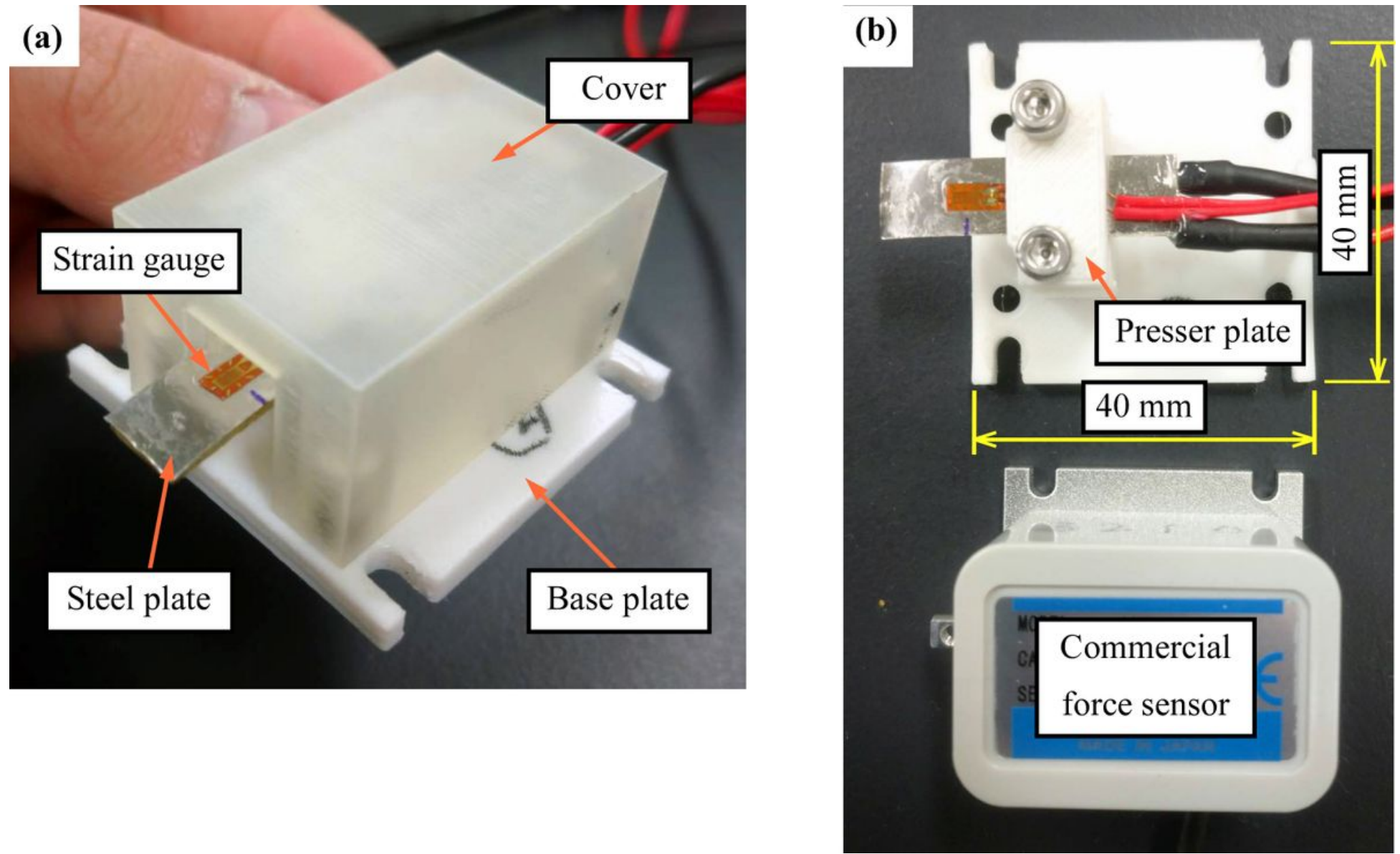

Figure 5

Prototype force sensor using SMP. (a) External appearance. (b) Internal components 


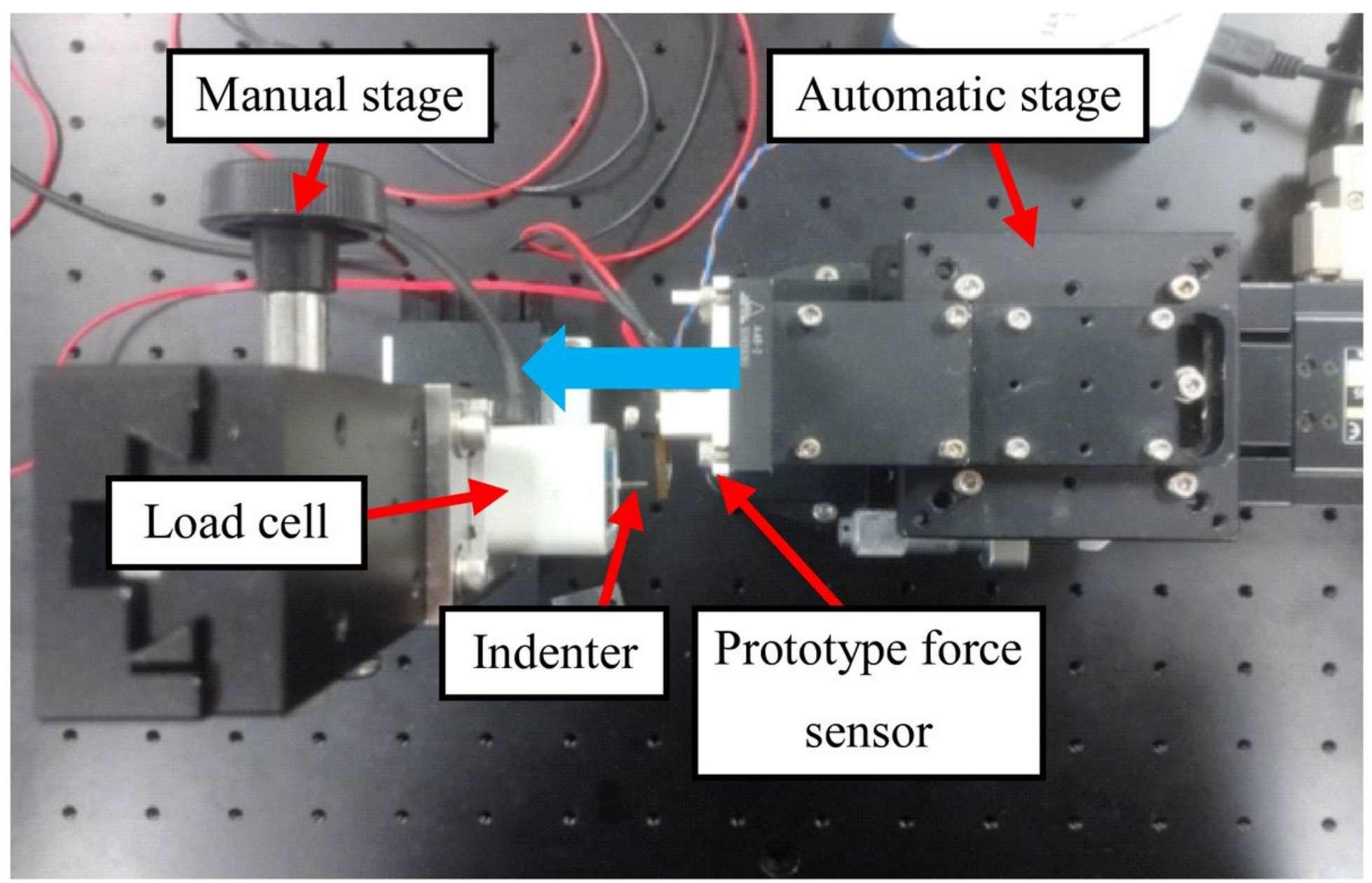

Figure 6

Experimental apparatus for evaluating force sensor. The prototype sensor was automatically displaced using an automatic stage 


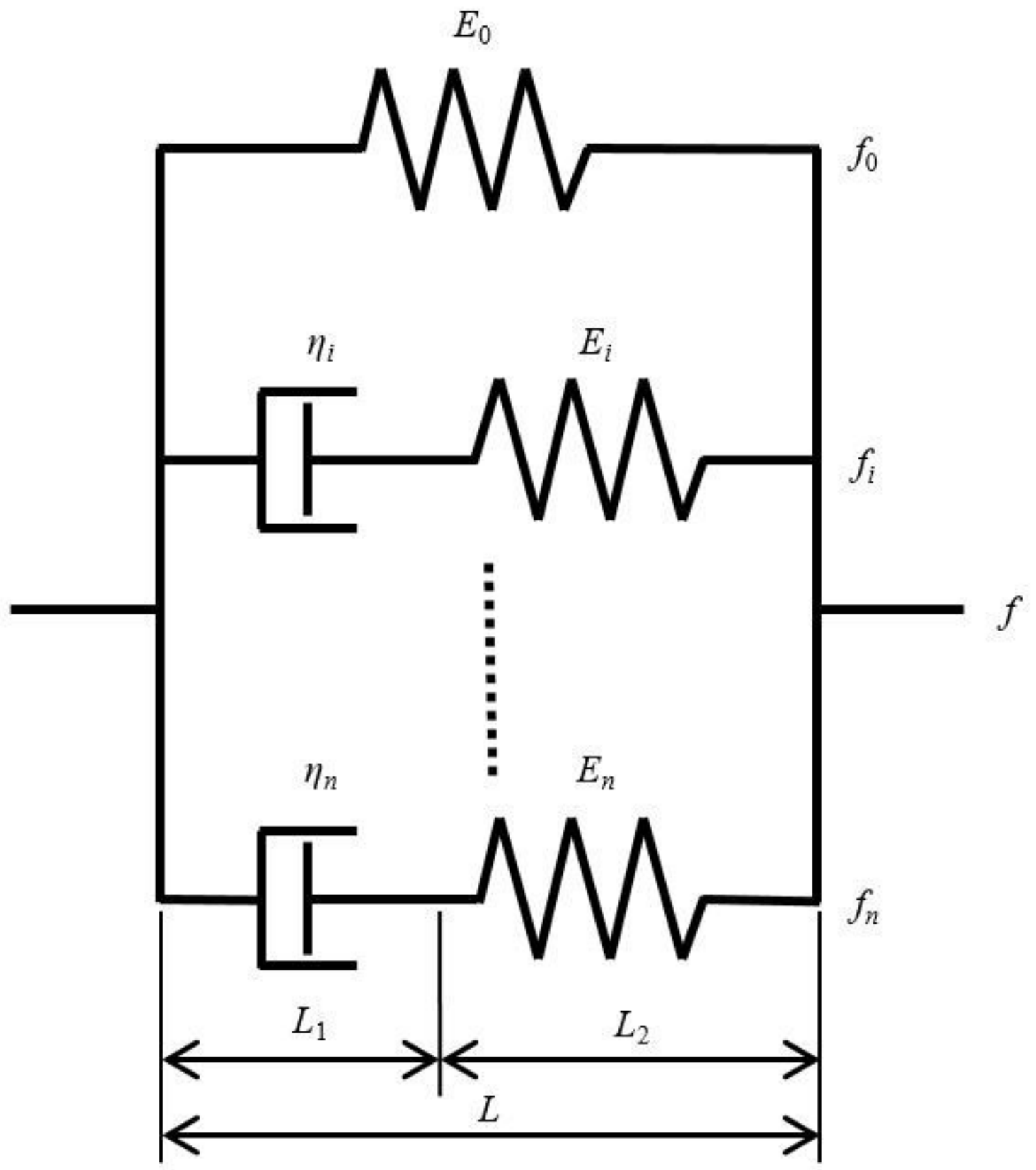

Figure 7

Generalized Maxwell model used in present study 
(a)

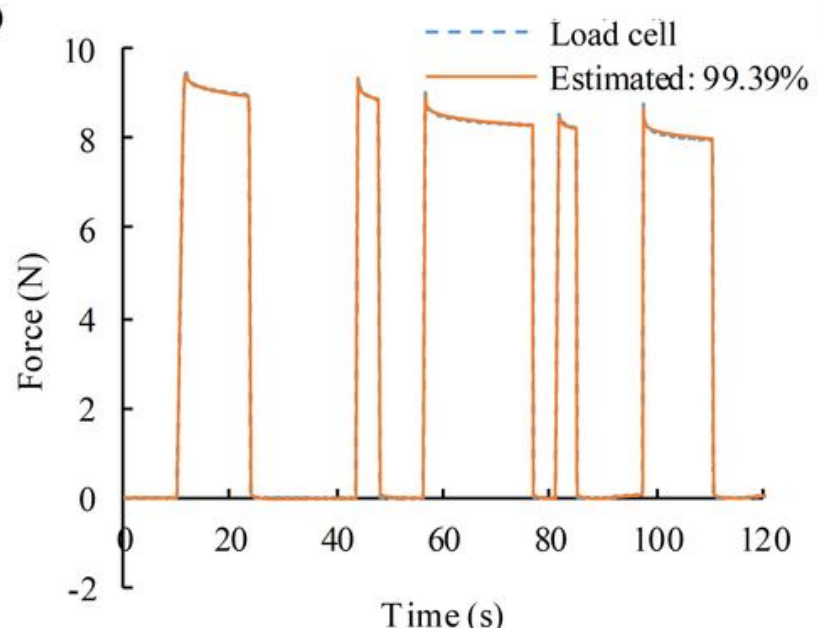

(c)

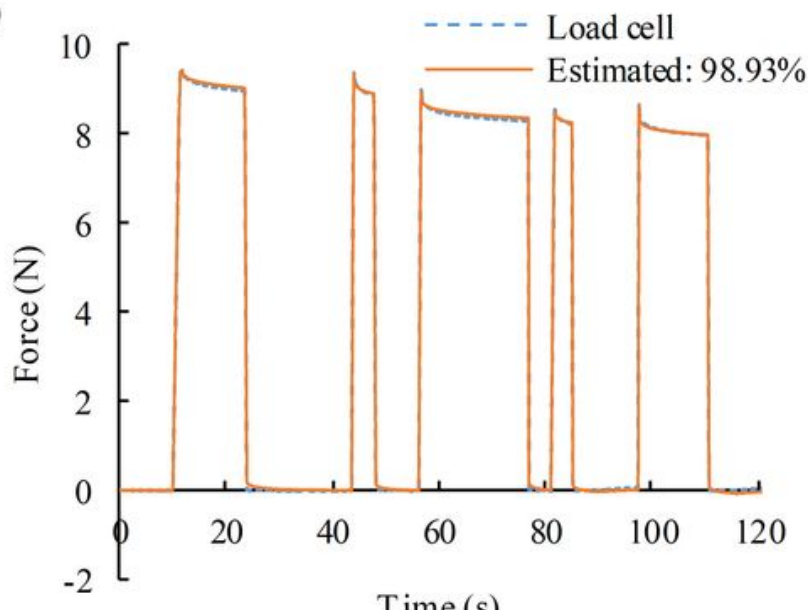

(e)

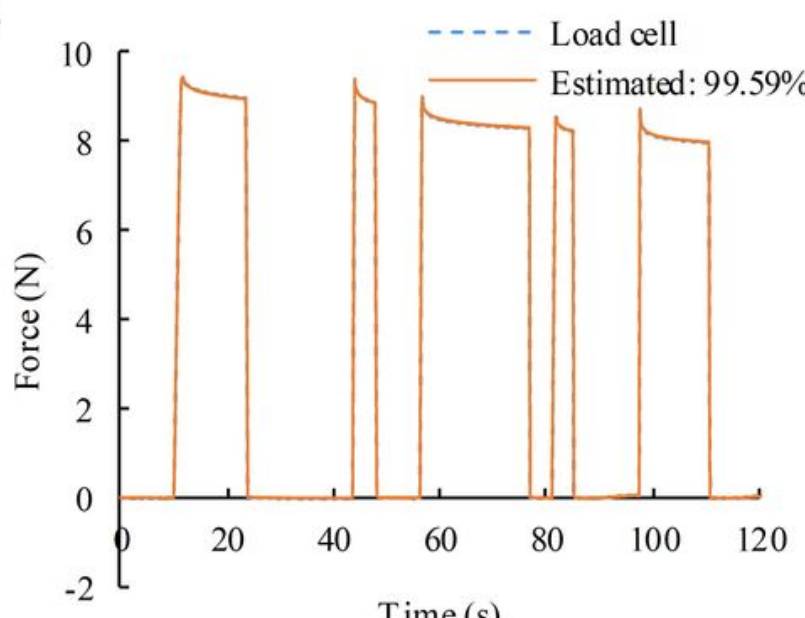

(b)

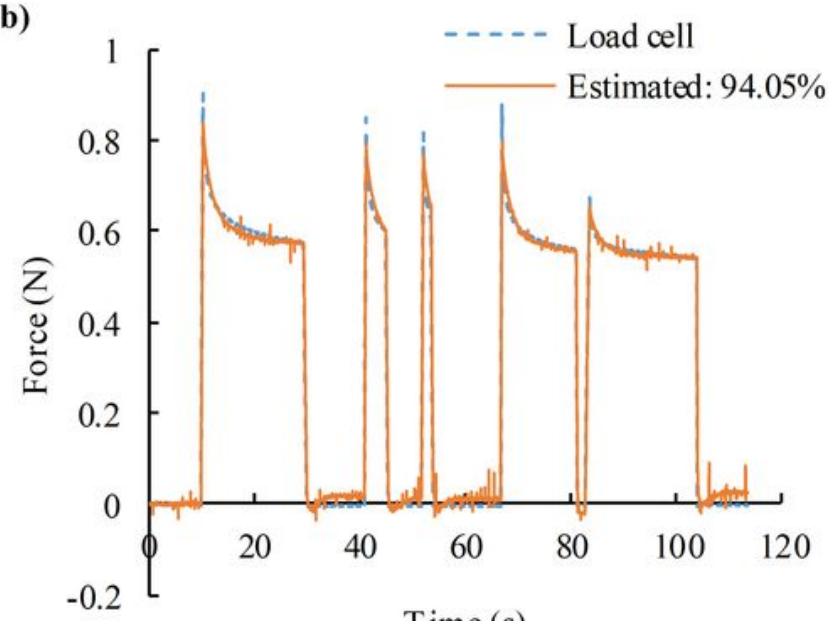

(d)

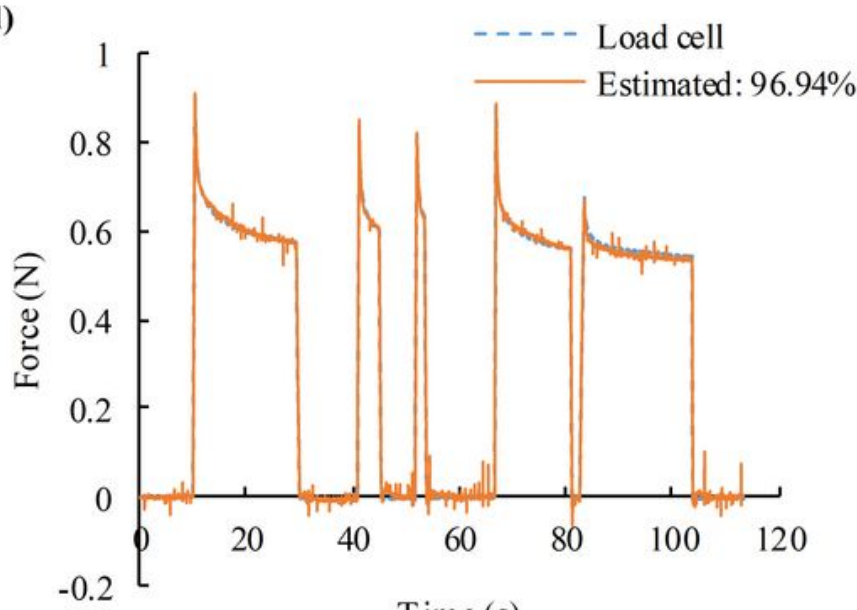

(f)

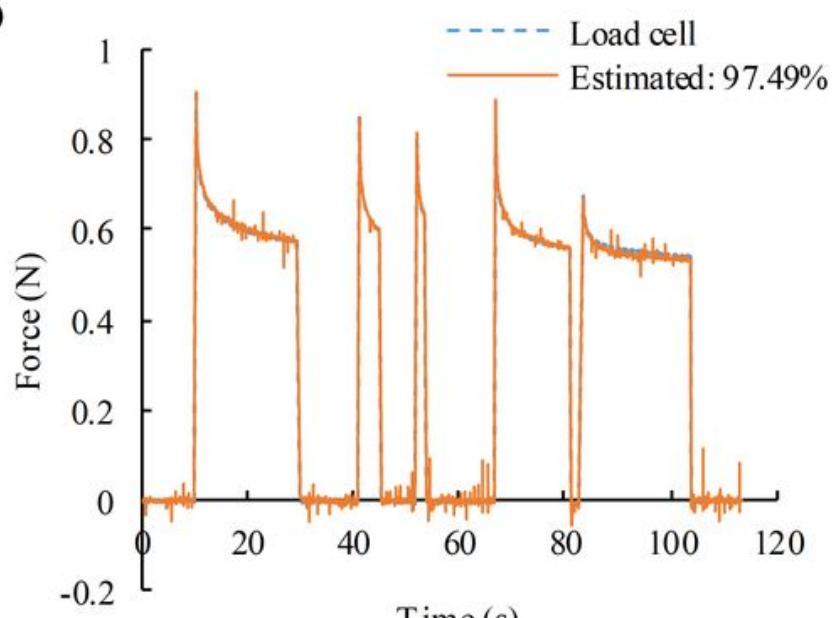

Figure 8

Forces measured using prototype sensor and load cell when random force was applied. FIT values are shown in each figure. (a) $\operatorname{T}<\operatorname{Tg}(n=1)$. (b) $\operatorname{T}>\operatorname{Tg}(n=1)$. (c) $\operatorname{T}<\operatorname{Tg}(n=2)$. (d) $\operatorname{T}>\operatorname{Tg}(n=2)$. (e) $\operatorname{T}<\operatorname{Tg}(n$ = 3). (f) $\operatorname{T}>\operatorname{Tg}(\mathrm{n}=3)$ 
(a)

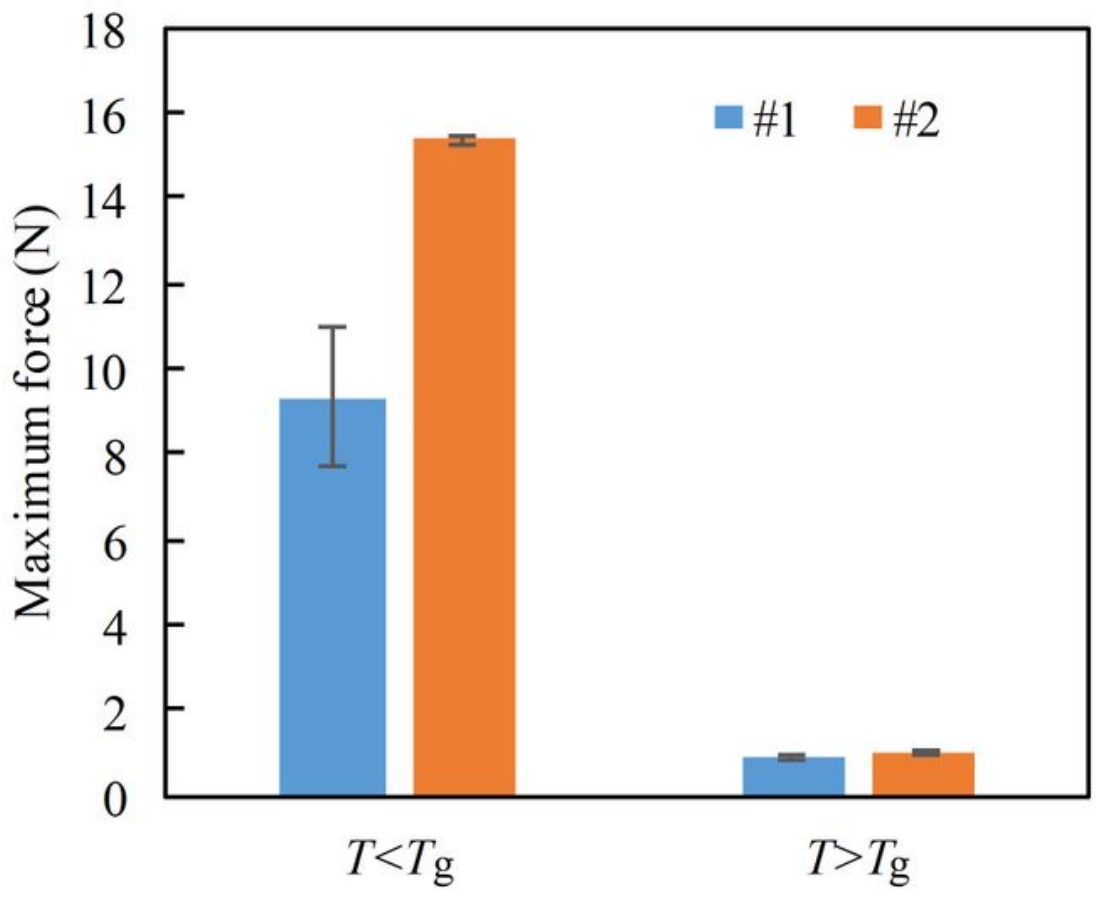

(b)

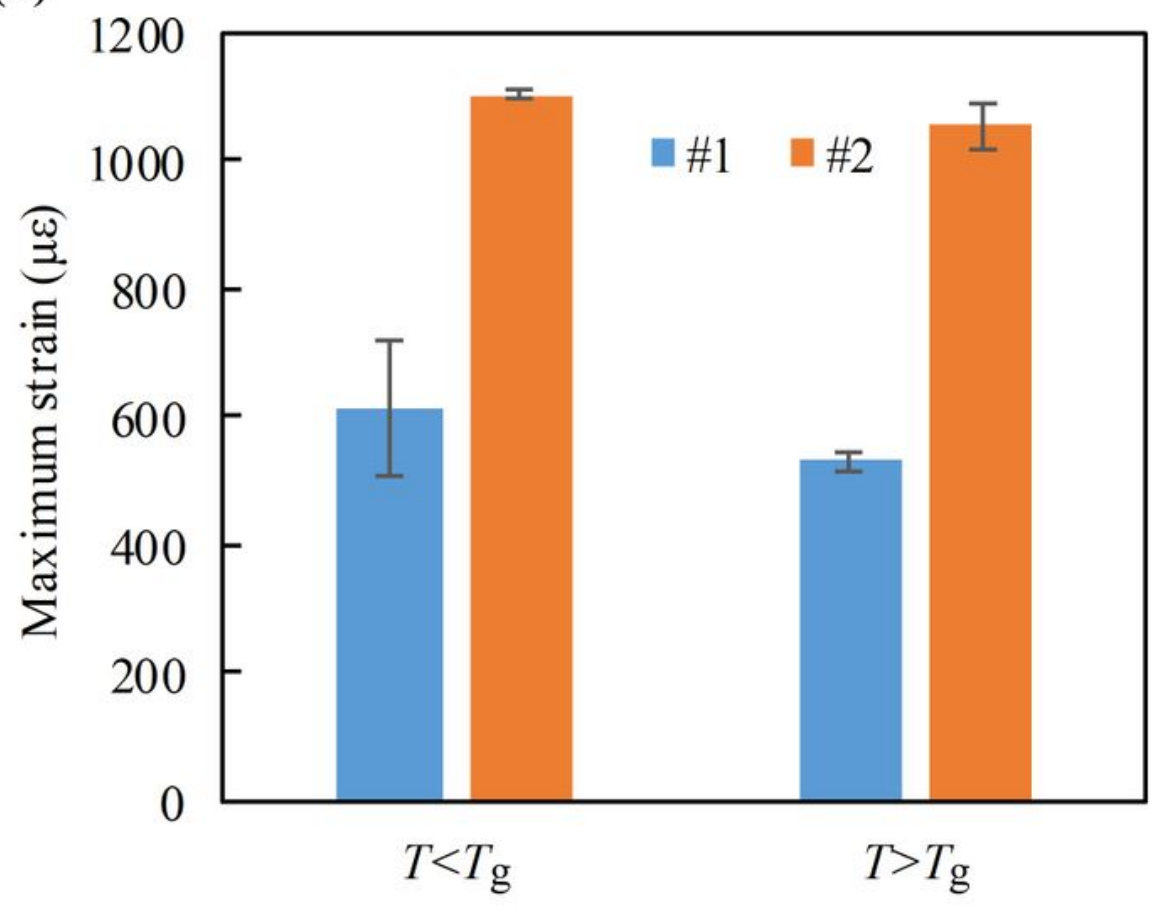

Figure 9

Maximum force (a) and strain (b) for different conditions 
(a)

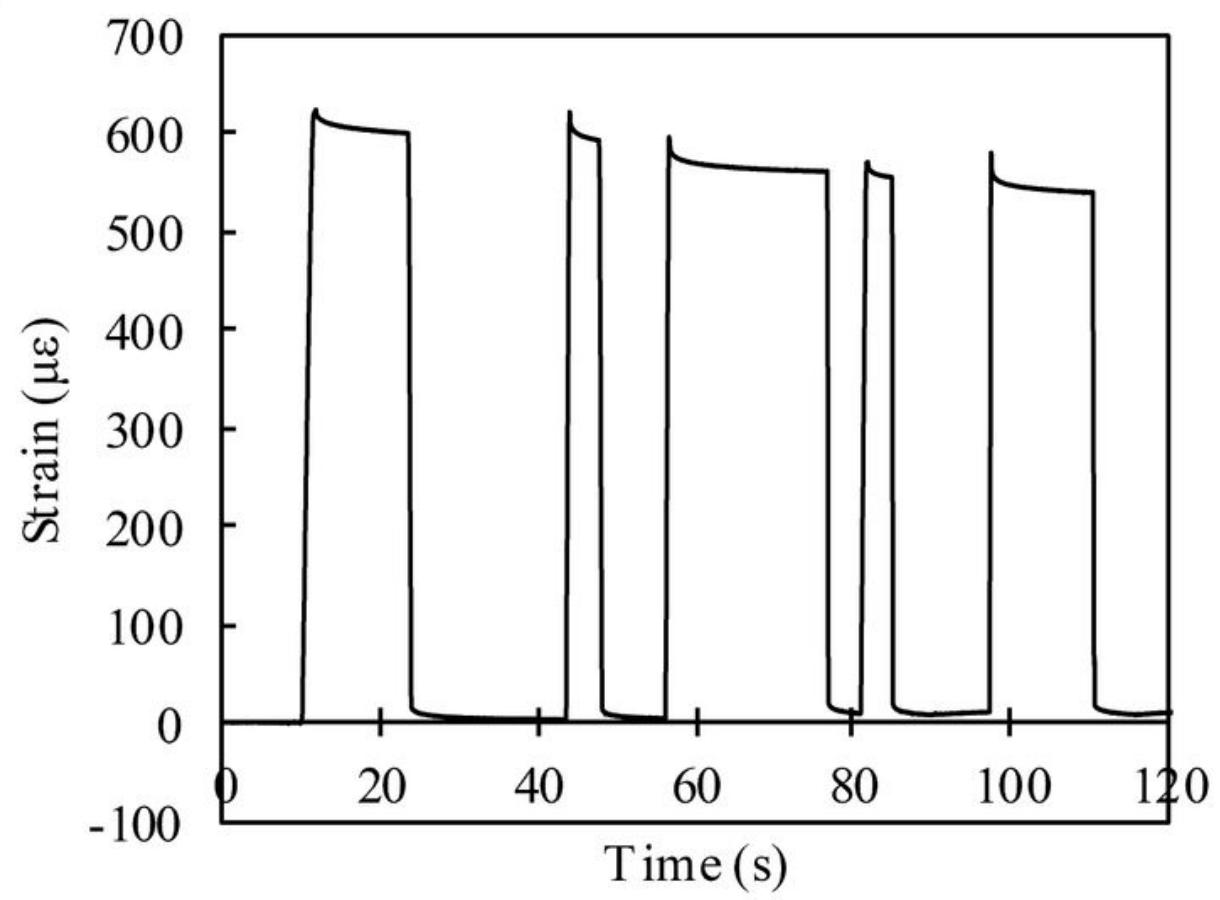

(b)

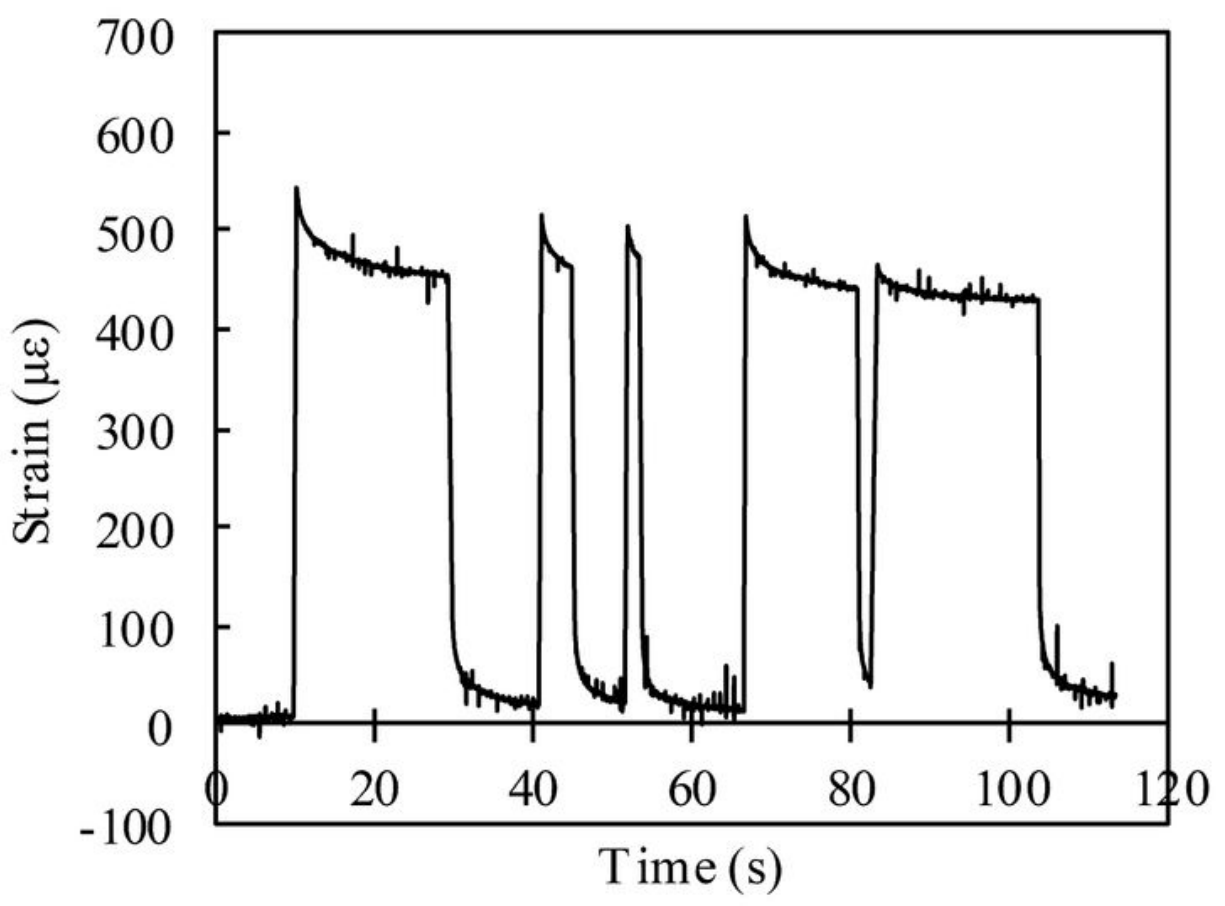

Figure 10

Transition of measured strain. (a) $\mathrm{T}<\mathrm{Tg}$. (b) $\mathrm{T}>\mathrm{Tg}$. We resampled the obtained $1-\mathrm{kHz}$ signal at $100 \mathrm{~Hz}$ using the resample() function of MATLAB 

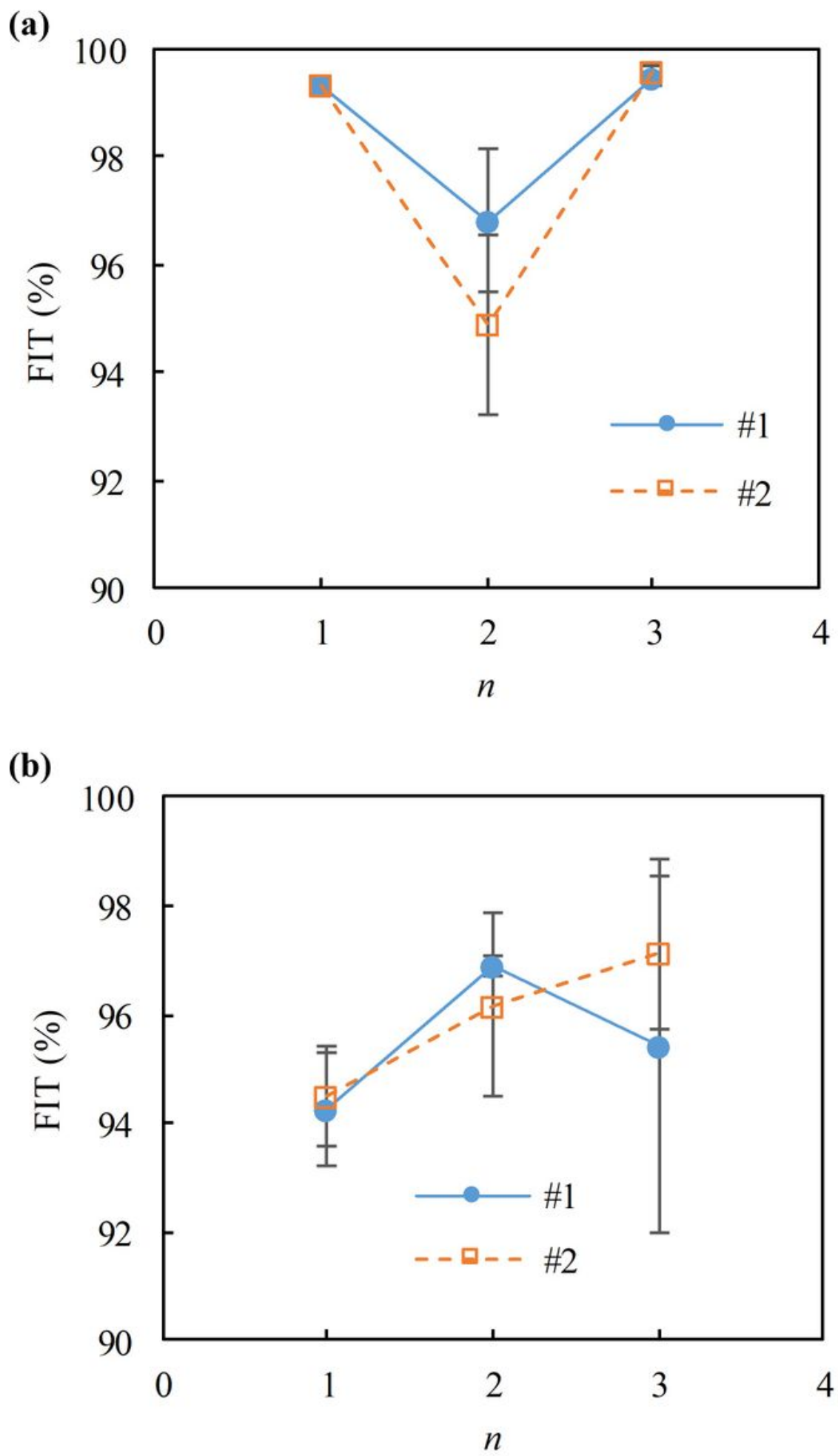

Figure 11

FIT values for different conditions. (a) $\mathrm{T}<\mathrm{Tg}$. (b) $\mathrm{T}>\mathrm{Tg}$ 


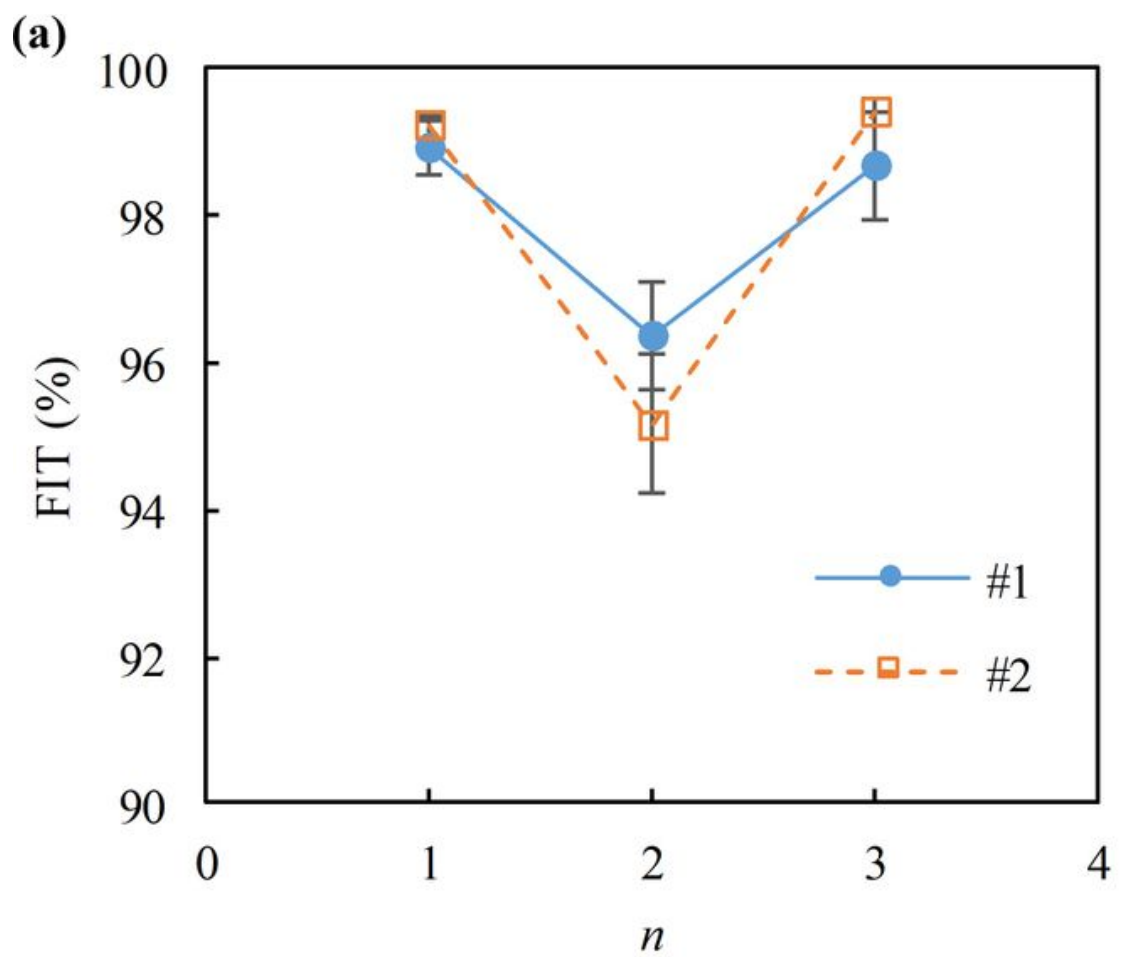

(b)

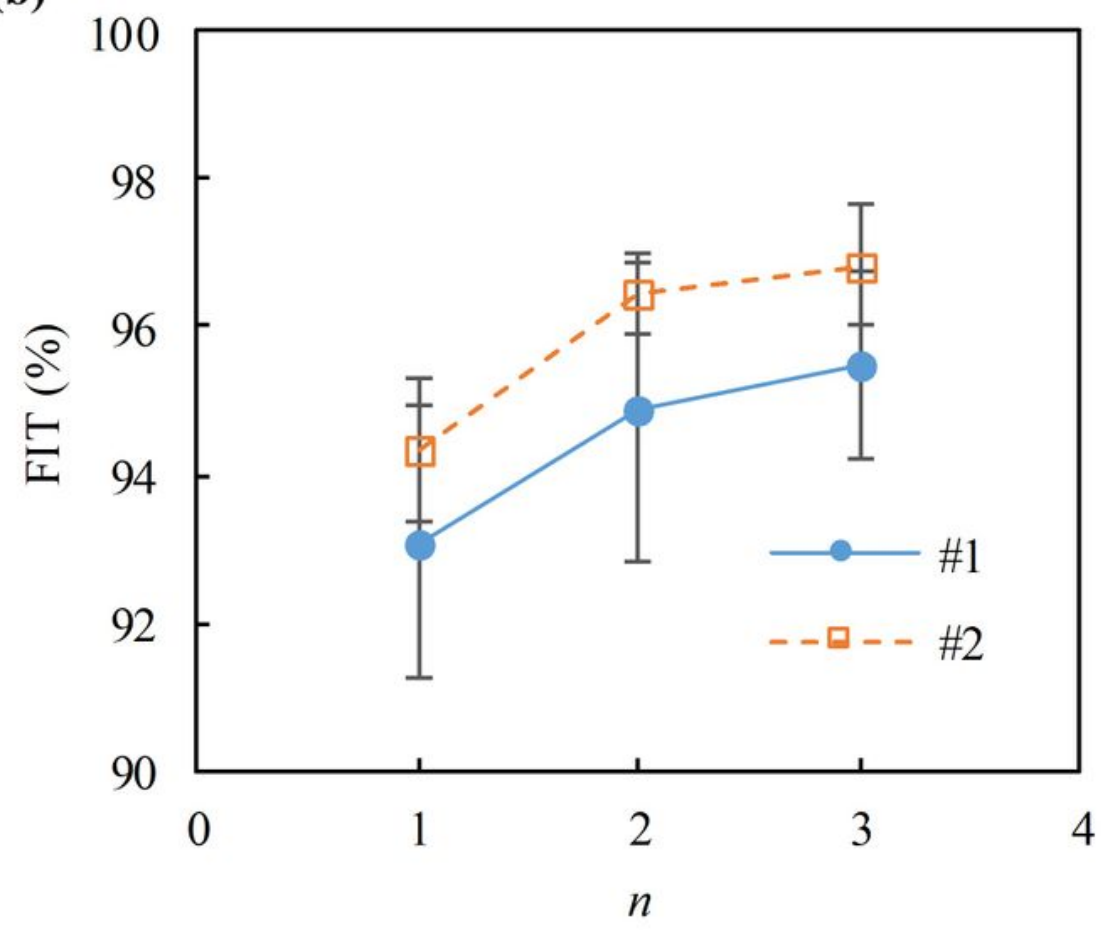

Figure 12

Average FIT values for different conditions. (a) $\mathrm{T}<\mathrm{Tg}$. (b) $\mathrm{T}>\mathrm{Tg}$ 
(a)
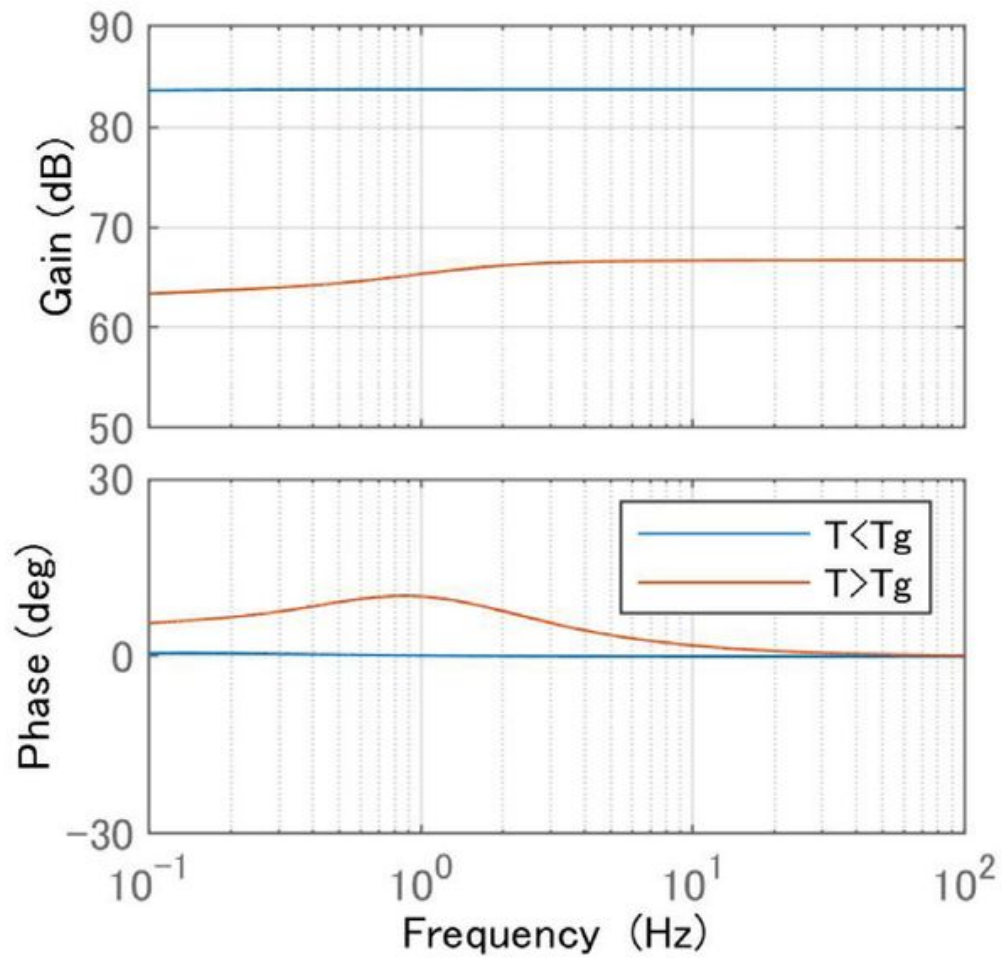

(b)
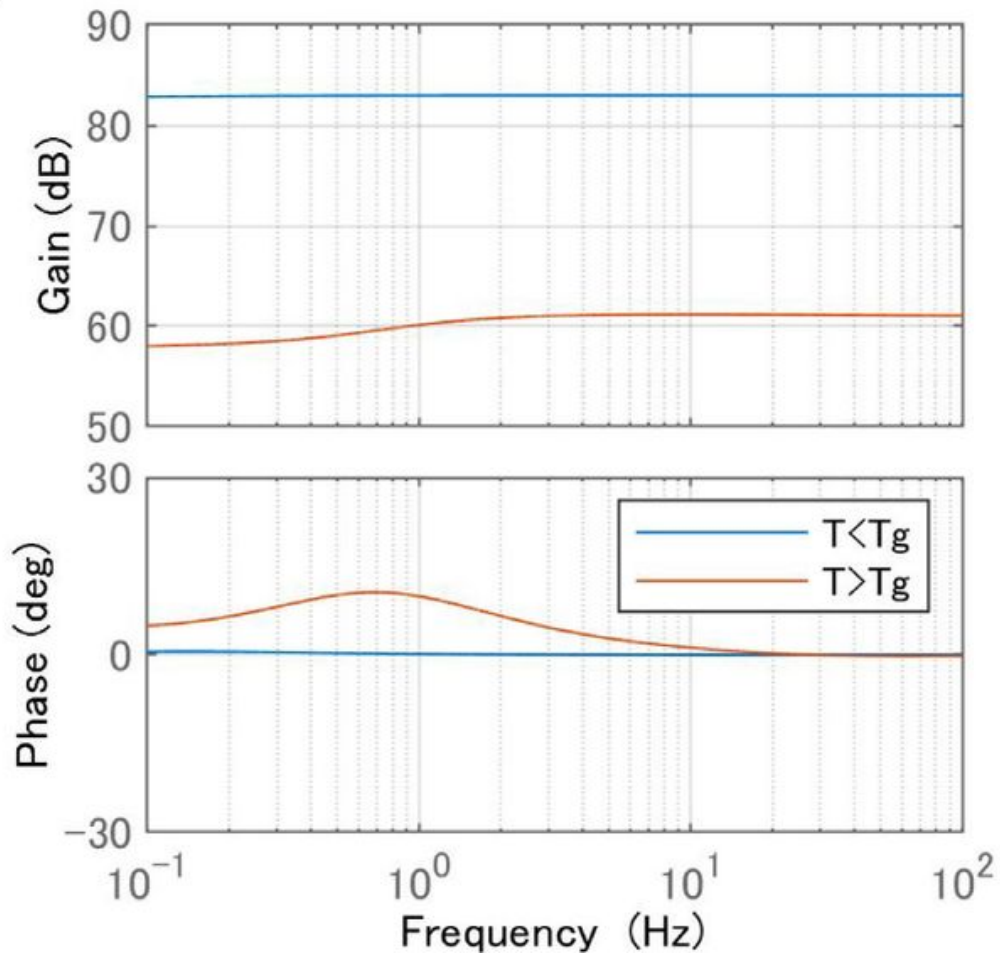

Figure 13

Frequency responses of transfer function obtained using Method 1. (a) \#1. (b) \#2 


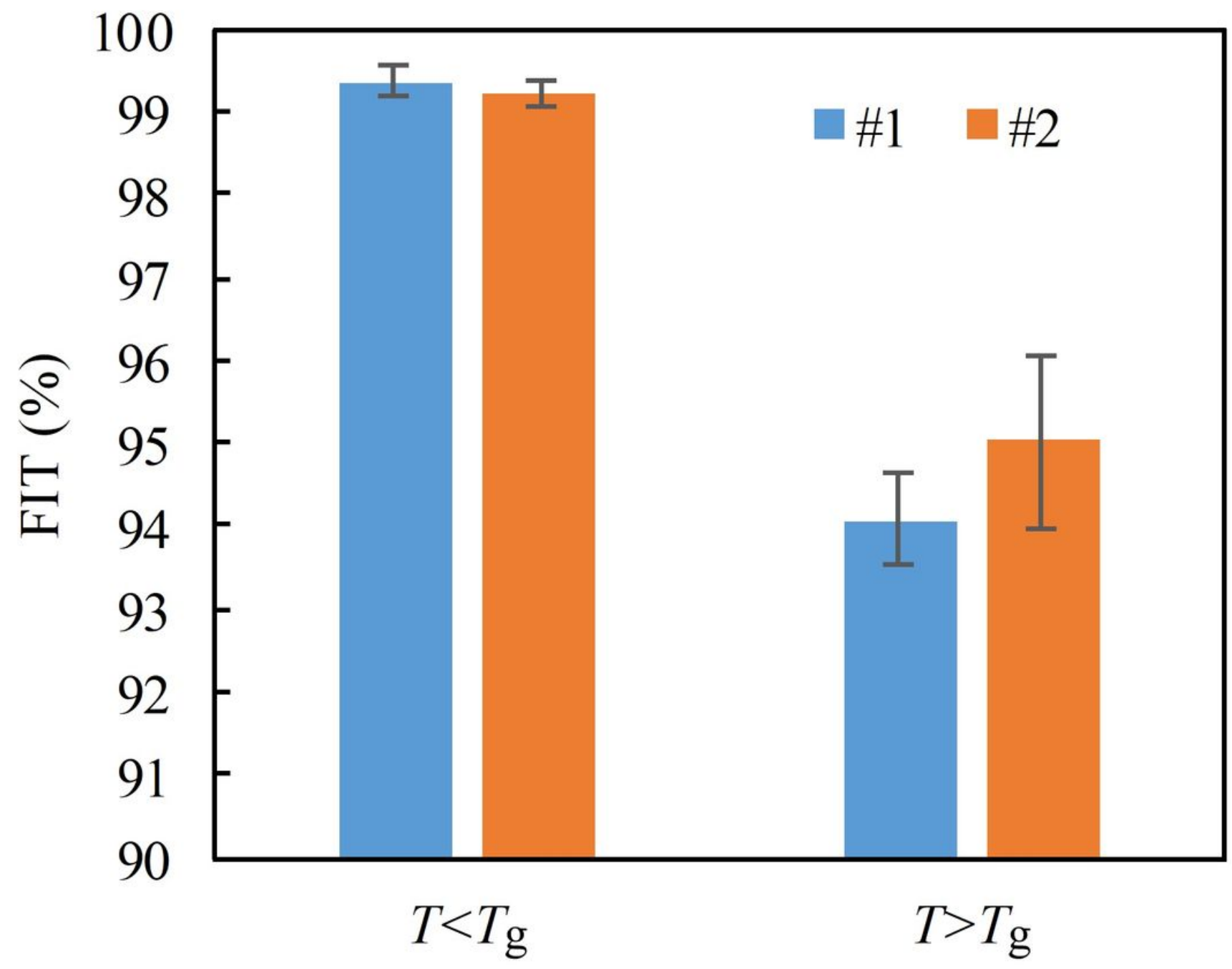

Figure 14

FIT value obtained using Method 2 
(a)
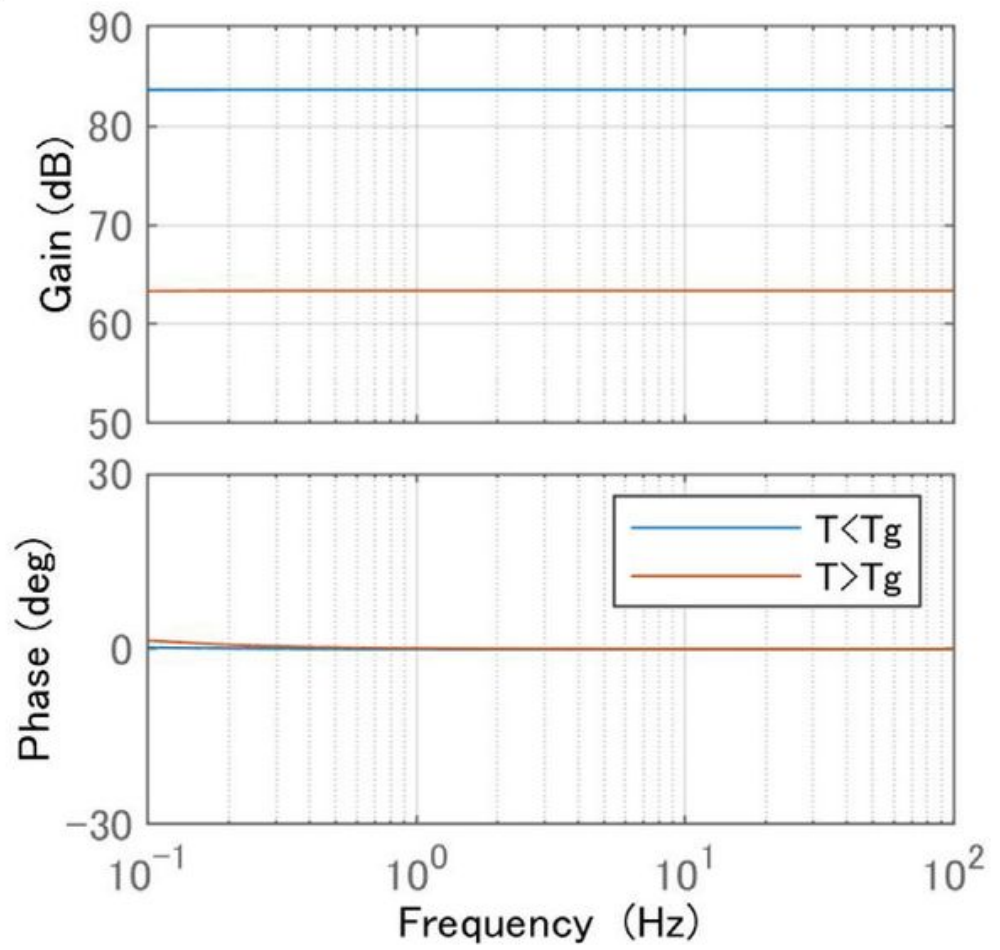

(b)
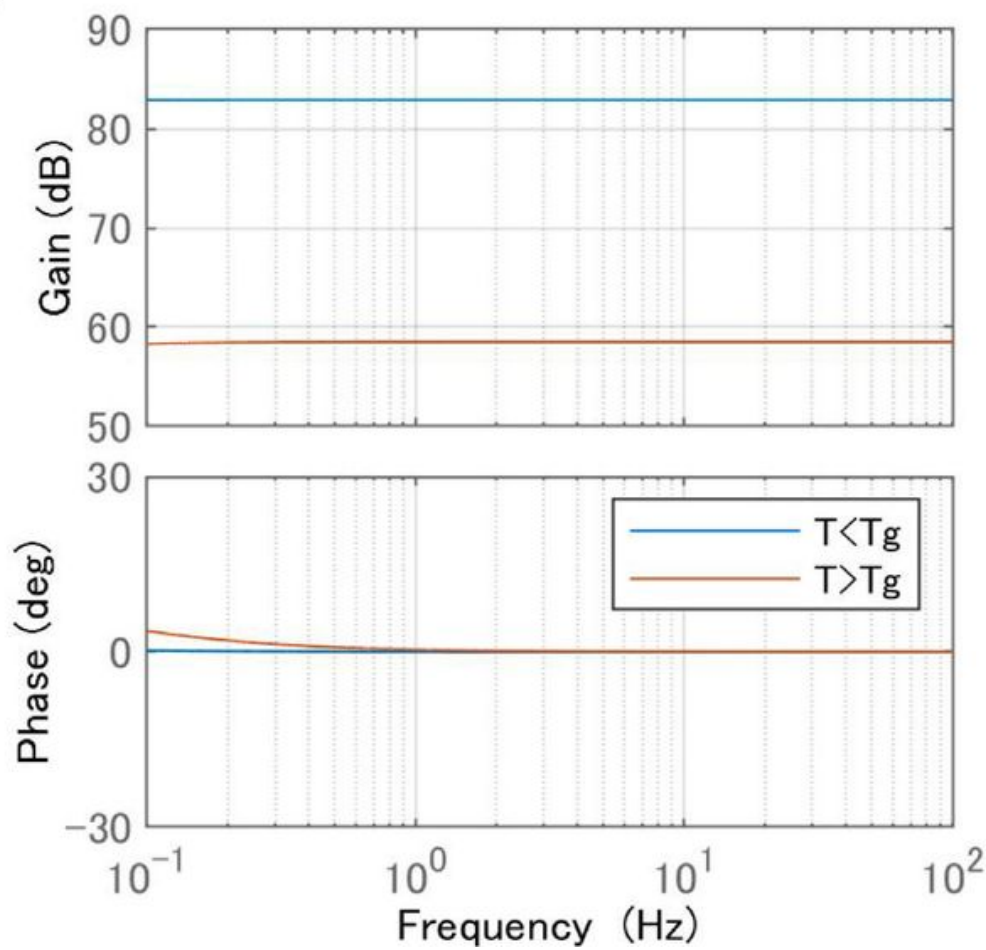

Figure 15

Frequency responses of transfer function obtained using Method 2. (a) \#1. (b) \#2 

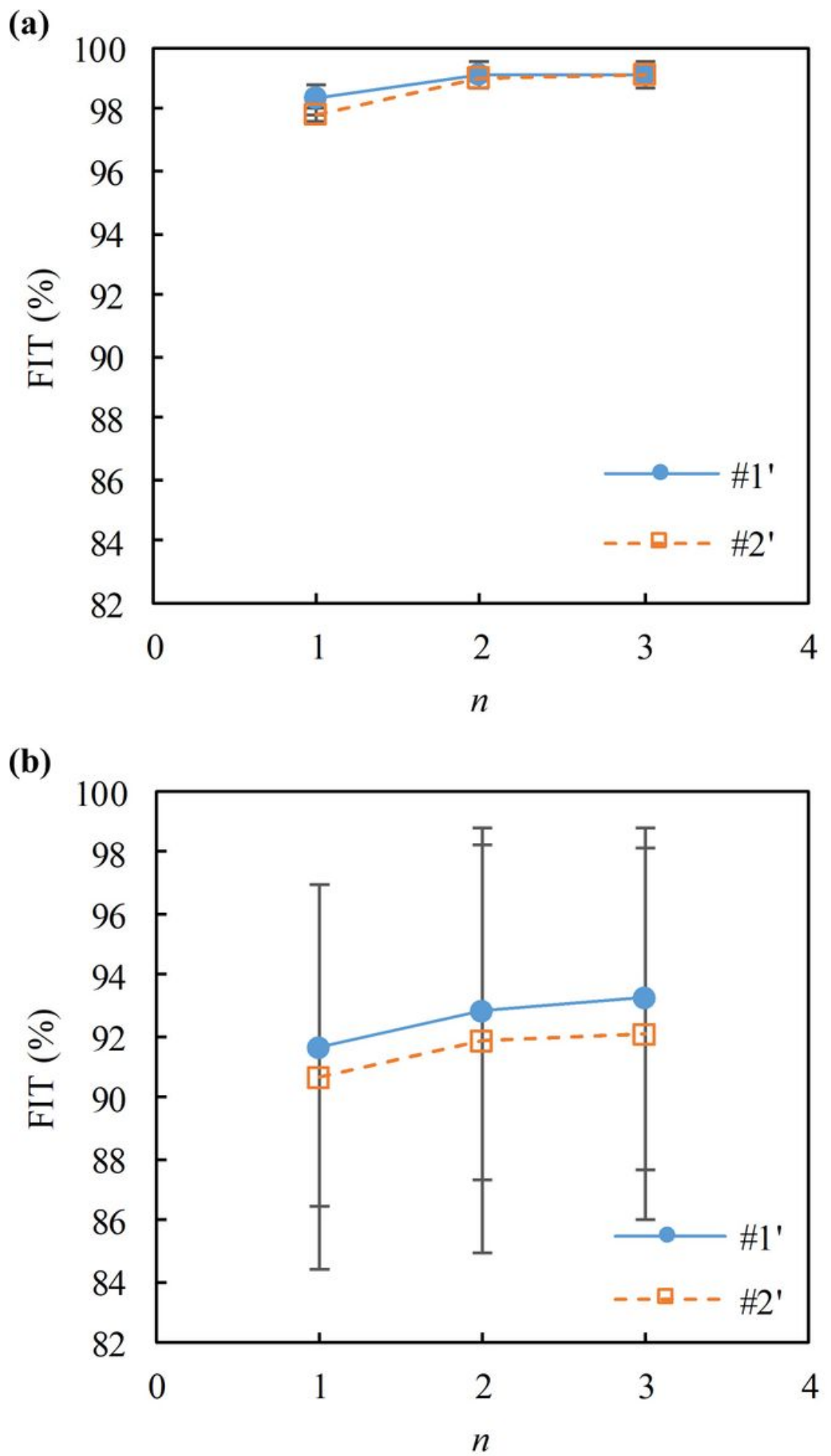

Figure 16

Step deformation response (FIT). (a) $\mathrm{T}<\mathrm{Tg}$. (b) $\mathrm{T}>\mathrm{Tg}$ 

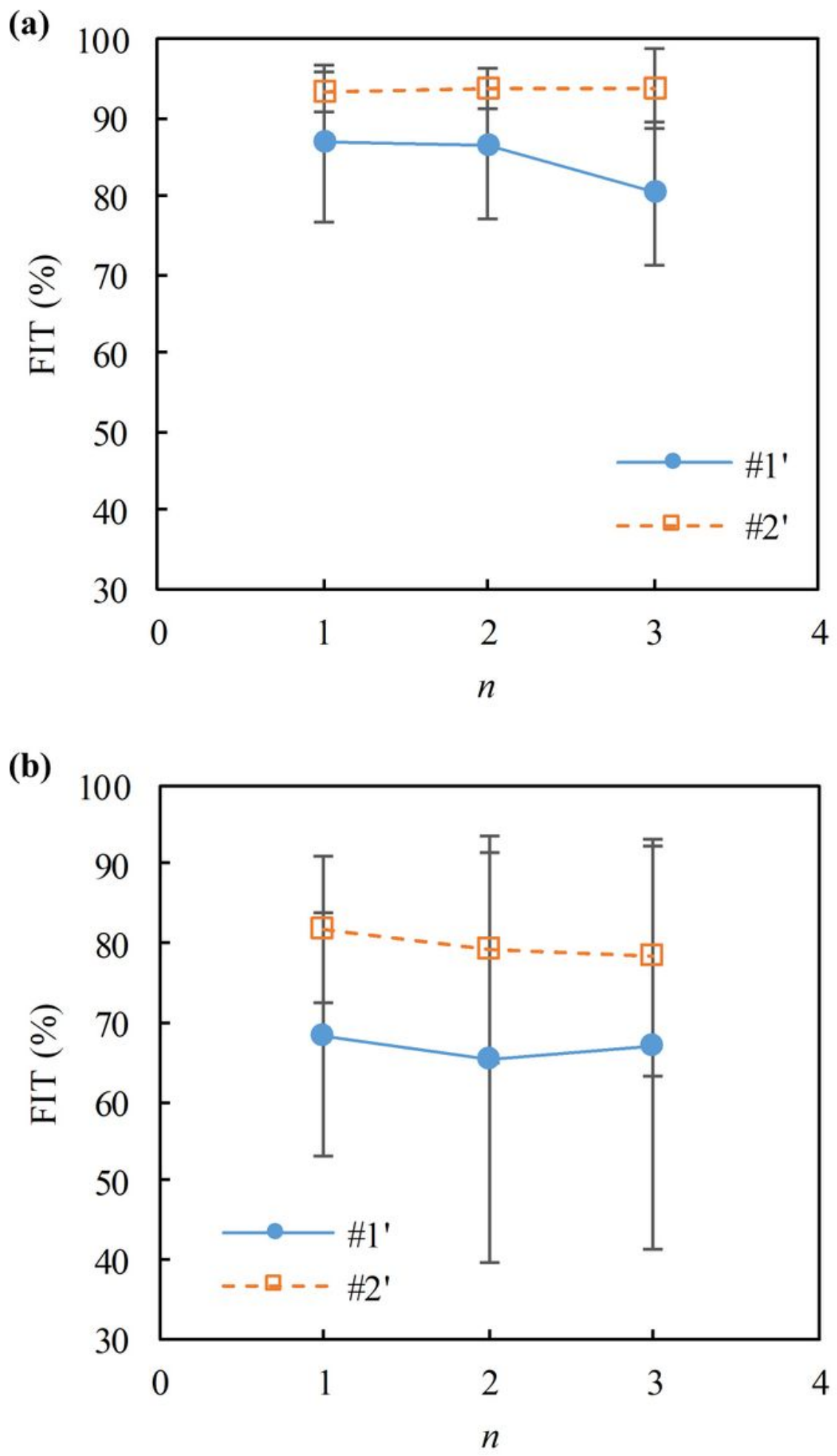

Figure 17

Average step deformation response (FIT). (a) $\mathrm{T}<\mathrm{Tg}$. (b) $\mathrm{T}>\mathrm{Tg}$ 